\title{
Formulated Chinese Medicine Shaoyao Gancao Tang Reduces Tau Aggregation and Exerts Neuroprotection through Anti-Oxidation and Anti-Inflammation
}

\author{
I-Cheng Chen $\left(\mathbb{D},{ }^{1}\right.$ Te-Hsien Lin $\left(\mathbb{D},{ }^{2}\right.$ Yu-Hsuan Hsieh, ${ }^{2}$ Chih-Ying Chao, ${ }^{1}$ Yih-Ru Wu $\left(\mathbb{D},{ }^{1}\right.$ \\ Kuo-Hsuan Chang $\mathbb{D},{ }^{1}$ Ming-Chung Lee, ${ }^{3}$ Guey-Jen Lee-Chen $\mathbb{i},{ }^{2}$ and Chiung-Mei Chen ${ }^{1}{ }^{1}$ \\ ${ }^{1}$ Department of Neurology, Chang Gung Memorial Hospital, Chang Gung University College of Medicine, Taipei 10507, Taiwan \\ ${ }^{2}$ Department of Life Science, National Taiwan Normal University, Taipei 11677, Taiwan \\ ${ }^{3}$ Sun Ten Pharmaceutical Co. Ltd., New Taipei City 23143, Taiwan
}

Correspondence should be addressed to Guey-Jen Lee-Chen; t43019@ntnu.edu.tw and Chiung-Mei Chen; cmchen@adm.cgmh.org.tw

Received 11 May 2018; Accepted 29 July 2018; Published 28 October 2018

Academic Editor: Francisco Jaime Bezerra Mendonça Júnior

Copyright ( 92018 I-Cheng Chen et al. This is an open access article distributed under the Creative Commons Attribution License, which permits unrestricted use, distribution, and reproduction in any medium, provided the original work is properly cited.

\begin{abstract}
Misfolded tau proteins induce accumulation of free radicals and promote neuroinflammation by activating microglia-releasing proinflammatory cytokines, leading to neuronal cell death. Traditional Chinese herbal medicines (CHMs) have been widely used in clinical practice to treat neurodegenerative diseases associated with oxidative stress and neuroinflammation. This study examined the neuroprotection effects of formulated CHMs Bai-Shao (made of Paeonia lactiflora), Gan-Cao (made of Glycyrrhiza uralensis), and Shaoyao Gancao Tang (SG-Tang, made of P. lactiflora and G. uralensis at 1:1 ratio) in cell model of tauopathy. Our results showed that SG-Tang displayed a greater antioxidative and antiaggregation effect than Bai-Shao and Gan-Cao and a stronger anti-inflammatory activity than Bai-Shao but similar to Gan-Cao. In inducible 293/SH-SY5Y cells expressing proaggregant human tau repeat domain $\left(\Delta \mathrm{K} 280 \mathrm{tau}_{\mathrm{RD}}\right)$, SG-Tang reduced tau misfolding and reactive oxygen species (ROS) level in $\Delta \mathrm{K} 280$ tau $_{\mathrm{RD}} 293$ cells and promoted neurite outgrowth in $\Delta \mathrm{K} 280$ tau $_{\mathrm{RD}} \mathrm{SH}-\mathrm{SY} 5 \mathrm{Y}$ cells. Furthermore, SG-Tang displayed anti-inflammatory effects by reducing nitric oxide (NO) production in mouse BV-2 microglia and increased cell viability of $\Delta \mathrm{K} 280 \mathrm{tau}_{\mathrm{RD}}$-expressing $\mathrm{SH}-\mathrm{SY} 5 \mathrm{Y}$ cells inflamed by BV-2 conditioned medium. To uncover the neuroprotective mechanisms of SG-Tang, apoptosis protein array analysis of inflamed tau expressing SH-SY5Y cells was conducted and the suppression of proapoptotic proteins was confirmed. In conclusion, SG-Tang displays neuroprotection by exerting antioxidative and anti-inflammatory activities to suppress neuronal apoptosis in human tau cell models. The study results lay the base for future applications of SG-Tang on tau animal models to validate its effect of reducing tau misfolding and potential disease modification.
\end{abstract}

\section{Introduction}

Neurodegenerative diseases including Alzheimer's disease (AD) and tauopathy are characterized by the presence of hyperphosphorylated, insoluble, and filamentous tau protein, which leads to neuronal dysfunction and loss [1]. Tau is an ubiquitously distributed microtubule-associated protein that promotes and stabilizes microtubule assembly. Aside from helping microtubule assembly, tau also interacts with other cytoskeleton components to play a role in axonal transport
[2]. Tau is encoded by MAPT (microtubule-associated protein tau) gene located on chromosome 17q21, containing 16 exons [3]. By alternative splicing, tau proteins exist as six different isoforms in human central nervous system (CNS). Exons 9-12 encode four C-terminal microtubule binding motifs which are imperfect copies of an 18-aminoacid tau repeat domain $\left(\operatorname{tau}_{\mathrm{RD}}\right)$. Different point mutations found in $\operatorname{tau}_{\mathrm{RD}}$ reduced the ability of tau to promote microtubule assembly [4] and accelerated aggregation of tau into filaments [5]. In addition, a single amino acid deletion 
$(\Delta \mathrm{K} 280)$ was found in patients with frontotemporal dementia and $\mathrm{AD}[6-8] . \Delta \mathrm{K} 280$ is extremely fibrillogenic and frequently used to model tau aggregation [9-11].

Emerging evidence has shown protein aggregation as a trigger for inflammation and neurodegeneration [12]. Activated microglia are found in the postmortem brain tissues of human tauopathy, and microglial burden correlated with tau burden in most of the pathologically afflicted areas $[13,14]$. Chronic activation of microglia may enhance the hyperphosphorylation of tau and the subsequent development of neurofibrillary tangles [15]. Activated microglia contribute to neurofibrillary pathology in $\mathrm{AD}$ through production of interleukin (IL)-1 and activation of neuronal p38-MAPK (mitogen-activated protein kinase 1) in vitro [16] and in vivo [17]. In transgenic mice that develop both tau and amyloid pathologies $(3 \times \mathrm{Tg}-\mathrm{AD}$ line $)$, lipopolysaccharide(LPS-) induced activation of glia exacerbates tau pathology [18]. Tau oligomers colocalize with astrocytes and microglia to induce inflammation, leading to neuronal damage and eventual cell death [19]. Being a critical component in pathogenesis, neuroinflammation provides an attractive therapeutic target in the treatment and prevention of $\mathrm{AD}$ and other tauopathy [20, 21].

Traditional Chinese herbal medicines (CHMs) have accumulated several lines of beneficial evidence in the treatment of $\mathrm{AD}$ [22-24]. However, treatment approaches addressing inflammatory processes in tauopathy have not been well investigated. Bai-Shao and Gan-Cao are formulated CHMs prepared from herbs Paeonia lactiflora (P. lactiflora) and Glycyrrhiza uralensis (G. uralensis), respectively. Total glucosides of paeony extracted from $P$. lactiflora may exert anti-inflammatory activities that contribute to its analgesic effect through modulating production of proinflammatory cytokines from macrophage-like synoviocytes [25]. In addition, ethanol extracts of $G$. uralensis possess inhibitory effects against NF- $\kappa \mathrm{B}$-mediated inflammatory response and strong activation of the Nrf2-ARE-antioxidative stress signaling pathways [26]. In this study, Bai-Shao, Gan-Cao, and Shaoyao Gancao Tang (SG-Tang), a formulated CHM made of $P$. lactiflora and $G$. uralensis at 1:1 ratio, were tested in a tau aggregation model [27] to reveal underlying pathogenesis and develop therapeutic strategy targeting neuroinflammation in tauopathy.

\section{Materials and Methods}

2.1. Preparation of Formulated CHMs. Bai-Shao (Code: 5722), Gan-Cao (Code: 5536), and SG-Tang (Code: 0703H) were provided by Sun Ten Pharmaceutical Co. Ltd. (New Taipei City, Taiwan). To prepare the CHM stock solution,

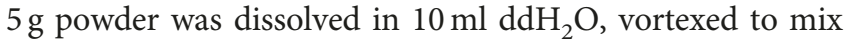
well, and then centrifuged at $4000 \mathrm{rpm}$ for $10 \mathrm{~min}$ at room temperature. The supernatant was collected and used for further experiments.

2.2. HPLC Analysis. High-performance liquid chromatography (HPLC) was performed using a LaChrom Elite HPLC system (Hitachi, Tokyo, Japan) equipped with photodiode array detector. The chromatographic separation of Bai-Shao,
Gan-Cao, and SG-Tang (500 mg/ml) was achieved using a Hypersil ODS (C18) column $(250 \times 4.6 \mathrm{~mm}, 5 \mu \mathrm{m})$. The mobile phase consisted of $0.1 \%$ phosphoric acid in water (A) and acetonitrile (B). The linear gradient elution was used as follows: $10 \sim 50 \% \mathrm{~B}(0 \sim 40 \mathrm{~min}), 50 \sim 90 \% \mathrm{~B}$ (40 45 $\mathrm{min})$, $90 \%$ B (45 55 min), 90 10\% B (55 60 min), and $10 \% \mathrm{~B}$ $(60 \sim 70 \mathrm{~min})$. The flow rate was $0.8 \mathrm{ml} / \mathrm{min}$. The column and autosampler were maintained at $30^{\circ} \mathrm{C}$ and $20^{\circ} \mathrm{C}$, respectively. Reference compounds were paeoniflorin and ammonium glycyrrhizinate (Sigma-Aldrich, St. Louis, MO, USA) and absorbance was monitored at $230 \mathrm{~nm}$ and $250 \mathrm{~nm}$, respectively. The scan range for photo diode array was 190 600 nm. 3-(4,5-Dimethylthiazol-2-yl)-2,5-diphenyltetrazolium bromide (MTT), 1,1-diphenyl-2-picrylhydrazyl (DPPH), LPS, and Congo red were purchased from SigmaAldrich. Interferon- (IFN-) $\gamma$ was obtained from Santa Cruz.

2.3. Cell Culture. Two mouse cell lines, RAW 264.7 macrophage (BCRC 60001, Food Industry Research and Development Institute, Taiwan) and BV-2 microglia (kind gift from Dr. Han-Min Chen, Catholic Fu-Jen University, New Taipei City, Taiwan), were used in this study. The murine RAW 264.7 and microglial BV-2 cells were routinely maintained in DMEM supplemented with 10\% FBS (Invitrogen, Waltham, MA, USA) at $37^{\circ} \mathrm{C}$ under $5 \% \mathrm{CO}_{2}$ and $95 \%$ relative humidity.

Four human cell lines, HEK-293 cells (ATCC no. CRL1573), SH-SY5Y neuronal cells (ATCC no. CRL-2266) and Tet-on $\Delta \mathrm{K} 280 \mathrm{tau}_{\mathrm{RD}}$-DsRed 293/SH-SY5Y cells [27] were used. HEK-293 cells were grown in DMEM with 10\% FBS, and SH-SY5Y cells were maintained in DMEM-F12 with $10 \%$ FBS. In addition to the basal media for HEK-293 and SH-SY5Y, $5 \mu \mathrm{g} / \mathrm{ml}$ blasticidin and $100 \mu \mathrm{g} / \mathrm{ml}$ hygromycin (InvivoGen, San Diego, CA, USA) were applied for Tet-On $\Delta \mathrm{K} 280$ tau $_{\mathrm{RD}}$-DsRed cells.

2.4. MTT Assay. To evaluate cell viability, $5 \times 10^{4} \mathrm{HEK}-293 /$ SH-SY5Y cells were plated into 48-well dishes, grown for $20 \mathrm{~h}$, and treated with tested Chinese medicine formulas $(0.1 \sim 1000 \mu \mathrm{g} / \mathrm{ml}$ Bai-Shao, Gan-Cao, or SG-Tang). After 1 day, $20 \mu \mathrm{l}$ of $5 \mathrm{mg} / \mathrm{ml} \mathrm{MTT}$ was added onto each 48 -well containing cells with $200 \mu \mathrm{l}$ of cultured medium at $37^{\circ} \mathrm{C}$ for $3 \mathrm{~h}$. $200 \mu \mathrm{l}$ of lysis buffer (10\% Triton X-100, $0.1 \mathrm{~N} \mathrm{HCl}, 18 \%$ isopropanol) was then added onto 48 -well and the absorbance at OD $570 \mathrm{~nm}$ was read by a microplate reader (FLx800 fluorescence microplate reader, Bio-Tek, Winooski, VT, USA). The half maximal inhibitory concentration $\left(\mathrm{IC}_{50}\right)$ were calculated using the interpolation method.

2.5. DPPH Assay. The DPPH radical-scavenging activity was measured in a reaction mixture containing $0.1 \mathrm{ml}$ of $0.2 \mathrm{mM}$ $\mathrm{DPPH}$ radical solution and $0.1 \mathrm{ml}$ of each tested formulas $(100 \sim 1000 \mu \mathrm{g} / \mathrm{ml})$. The solution was rapidly mixed and incubated for $30 \mathrm{~min}$ at $25^{\circ} \mathrm{C}$. The scavenging capacity was measured by monitoring the absorbance at $517 \mathrm{~nm}$ with a microplate reader (Multiskan GO, Thermo Scientific, Waltham, MA, USA). The half maximal effective concentrations $\left(\mathrm{EC}_{50}\right)$ were calculated using the interpolation method. 
2.6. Detection of Inflammatory Mediators. Murine RAW 264.7 macrophage cells were seeded in DMEM containing $1 \%$ FBS and pretreated with tested formulas $(0.5 \sim 2 \mathrm{mg} / \mathrm{ml})$ or celecoxib $(50 \mu \mathrm{M})$ for $8 \mathrm{~h}$ followed by LPS $(1 \mu \mathrm{g} / \mathrm{ml})$ stimulation. The release of $\mathrm{NO}$ was evaluated by Griess assay according to the manufacturer's protocol (SigmaAldrich). The levels of tumor necrosis factor- (TNF-) $\alpha$, IL- $1 \beta$, and IL- 6 were determined using a mouse enzymelinked immunosorbent assay (ELISA) system (R\&D Systems, Minneapolis, MN, USA) following the manufacturer's protocol. The optical density at $450 \mathrm{~nm}$ was detected using a microplate reader (ELISA Reader: SpectraMAX340PC; Molecular Devices, Sunnyvale, CA, USA). In addition, the immortalized murine microglial BV-2 cells, an alternative model system for primary microglia, were used. BV-2 cells were seeded in DMEM containing 1\% FBS. Next day, cells were pretreated with SG-Tang for $8 \sim 24 \mathrm{~h}$, stimulated with LPS $(1 \mu \mathrm{g} / \mathrm{ml})$ for $20 \mathrm{~h}$, and released of $\mathrm{NO}$ in the media determined.

2.7. $\Delta K 280$ tau $_{R D}$-DsRed Fluorescence Assay. DsRed fluorescence was evaluated to reflect tau aggregation. On the first day, $\Delta \mathrm{K} 280$ tau $_{\mathrm{RD}}$-DsRed 293 cells were seeded into the 96well dish in a density of $0.8 \times 10^{4}$ cells/well and one day after seeding, $5 \sim 20 \mu \mathrm{M}$ Congo red or $50 \sim 200 \mu \mathrm{g} / \mathrm{ml}$ Bai-Shao, Gan-Cao, and SG-Tang were added. After $8 \mathrm{~h}$ of culture, doxycycline $(1 \mu \mathrm{g} / \mathrm{ml}$; Sigma-Aldrich) was added to induce misfolded tau expression. On the fifth day, cells were stained with Hoechst $33342(0.1 \mu \mathrm{g} / \mathrm{ml})$ for $30 \mathrm{~min}$, and fluorescence intensities $(543 \mathrm{~nm}$ excitation and $593 \mathrm{~nm}$ emission for DsRed; $377 \mathrm{~nm}$ excitation and $447 \mathrm{~nm}$ emission for Hoechst 33342) were measured using a high content analysis (HCA) system (ImageXpressMICRO, Molecular Devices). All images were analyzed by MetaXpress Image Acquisition and Analysis Software (Molecular Devices).

2.8. ROS Assay. Cellular ROS of the above Tet-On $\Delta \mathrm{K} 280$ tau $_{\mathrm{RD}}$-DsRed 293 cells was measured by fluorogenic reagent $\left(C e l l R O X^{\mathrm{TM}}\right.$ Deep Red, Molecular Probes, Eugene, OR, USA) with final concentration of $5 \mu \mathrm{M}$ and incubated at $37^{\circ} \mathrm{C}$ for $30 \mathrm{~min}$. Then, cells were washed with PBS and analyzed by flow cytometer (Becton-Dickinson, Franklin Lakes, NJ, USA) with excitation/emission wavelengths at 640/ $665 \mathrm{~nm}$. For each sample, $5 \times 10^{4}$ cells are analyzed.

2.9. Neurite Outgrowth Analysis. $3 \times 10^{4}$ of $\Delta \mathrm{K} 280$ tau $_{\mathrm{RD}^{-}}$ DsRed SH-SY5Y cells/well were seeded in a 24 -well plate, and $10 \mu \mathrm{M}$ retinoic acid (Sigma-Aldrich) was added to initiate neuronal differentiation. On the second day, cells were treated with SG-Tang $(200 \mu \mathrm{g} / \mathrm{ml})$ or Congo red $(20 \mu \mathrm{M})$ for $8 \mathrm{~h}$ before tau expression induction by adding doxycycline $(1 \mu \mathrm{g} / \mathrm{ml})$. On day 9 , cells were fixed in $4 \%$ paraformaldehyde in PBS for $15 \mathrm{~min}$, permeabilized in $0.1 \%$ Triton X-100 in PBS for $10 \mathrm{~min}$, and blocked in 3\% bovine serum albumin (BSA) in PBS for $20 \mathrm{~min}$. Primary TUBB3 antibody ( $1: 1000$ dilution in PBS with $1 \%$ BSA, $0.05 \%$ Tween 20 , and $0.02 \% \mathrm{NaN}_{3}$; Covance, Princeton, NJ, USA) was used to stain neuronal cells, followed by secondary goat anti-rabbit Alexa Fluor ${ }^{\circledR} 555$ antibody (1:1000 dilution; Molecular probes) at room temperature. After nuclei staining by $4^{\prime}-6$-diamidino-2-phenylindole (DAPI), images of cells were taken via the HCA system and analyzed as described.

2.10. Cell Viability/Cytotoxicity Assays of Inflamed SH-SY5Y Cells. Previously, cell-free media obtained from LPS/IFN- $\gamma$ exposed microglia-like cells resulted in the highest toxicity on cell viability of SH-SY5Y cells [28]. To prepare conditioned medium (CM) with inflammatory factors, BV-2 cells were stimulated with a combination of LPS $(1 \mu \mathrm{g} / \mathrm{ml})$ and IFN- $\gamma(100 \mathrm{ng} / \mathrm{ml})$ for $24 \mathrm{~h}$. After morphology examination, the BV-2 CM were collected, pooled, and centrifuged to remove cell debris. The induced inflammation was confirmed by release of NO, TNF- $\alpha$, IL- $1 \beta$, and IL- 6 in the media and increased Ibal expression in the cell lysate.

For SH-SY5Y cell viability assay, DMEM-F12 was then mixed with two times volume of BV-2 CM (a final FBS concentration at $10 \%)$ and added to undifferentiated $\Delta \mathrm{K} 280$ $\operatorname{tau}_{\mathrm{RD}}$-DsRed SH-SY5Y cells for 2 days to induce inflammation. Cell viability was determined by MTT assay as described. For SH-SY5Y cytotoxicity assay, neuronaldifferentiated $\Delta \mathrm{K} 280$ tau $_{\mathrm{RD}}$-DsRed SH-SY5Y cells were treated with BV-2 CM for 5 days as described and media were collected. $100 \mu \mathrm{l}$ of supernatant from each sample was transferred to 96 -well plate to examine the release of lactate dehydrogenase (LDH) by using LDH cytotoxicity assay kit (Cayman, Ann Arbor, MI, USA). The absorbance was read at $490 \mathrm{~nm}$ with a microplate reader (Multiskan GO, Thermo Scientific).

2.11. Human Apoptosis Antibody Array. Protein samples from $\Delta \mathrm{K} 280 \mathrm{tau}_{\mathrm{RD}}$-DsRed $\mathrm{SH}-\mathrm{SY} 5 \mathrm{Y}$ cells with different treatments (Dox uninduced/induced, CM unstimulated/ stimulated, and SG-Tang unpretreated/pretreated) were prepared and incubated with apoptosis antibody array membranes (RayBiotech, Norcross, GA, USA). The relative levels of 43 apoptosis-related proteins in human cell lysates were measured with the array. The detected changes in protein levels were confirmed by Western blot or caspase 3 activity assay.

2.12. Western Blot Analysis. Cells were lysed in hypotonic buffer $\left(20 \mathrm{mM}\right.$ HEPES pH 7.4, $1 \mathrm{mM} \mathrm{MgCl}_{2}, 10 \mathrm{mM} \mathrm{KCl}$, $1 \mathrm{mM}$ DTT, $1 \mathrm{mM}$ EDTA pH 8.0) containing the protease inhibitor mixture (Sigma-Aldrich). After sonication and sitting on ice for $20 \mathrm{~min}$, the lysates were centrifuged at $14000 \times g$ for $30 \mathrm{~min}$ at $4^{\circ} \mathrm{C}$. Protein concentrations were determined using the Bio-Rad protein assay kit (Bio-Rad, Hercules, CA, USA), with albumin as standards. Total proteins $(25 \mu \mathrm{g})$ were electrophoresed on $10 \%$ or $12 \%$ SDSpolyacrylamide gel and transferred onto nitrocellulose membrane (Bio-Rad) by reverse electrophoresis. After being blocked, the membrane is stained with Ibal (1:500; Wako, Osaka, Japan), Tau (1:200; Dako, Santa Clara, CA, USA), p-Tau Ser202 (1:200; Fremont, CA, USA), p-Tau Thr231 (1:500, Invitrogen), p-Tau Ser396 (1:500; Invitrogen), BID ( 1 : 1000; Cell Signaling, Danvers, MA, USA), BAD (1:500; Santa Cruz, Dallas, TX, USA), CYCS (1:500; Biovision, Milpitas, CA, USA), CASP8 (1:1000; Cell Signaling), DsRed 
(1:500; Santa Cruz), tubulin (1:1000; Sigma-Aldrich), or GAPDH $(1: 1000$, MDBio) primary antibodies. The immune complexes are detected using horseradish peroxidaseconjugated goat anti-mouse (Jackson ImmunoResearch, West Grove, PA, USA) or goat anti-rabbit (Rockland, Pottstown, PA, USA) IgG antibody (1:10000 dilution) and ImmobilonTM Western Chemiluminescent HRP substrate (Millipore, Billerica, MA, USA).

2.13. Caspase 3 Activity Measurement. Cells were lysed in $1 \times$ lysis buffer by repeated cycles of freezing and thawing. Caspase 3 activity was measured with the caspase 3 assay kit according to the manufacturer's instructions (SigmaAldrich).

2.14. Statistical Analysis. For each set of values, data are represented as mean $\pm \mathrm{SD}$ of three independent experiments. Differences between groups were evaluated by two-tailed Student's $t$-test or ANOVA (one-way and two-way) with post hoc LSD test where appropriate. $p$ values $<0.05$ were considered significant.

\section{Results}

3.1. Formulated CHMs and Cytotoxicity. Three formulated CHMs, Bai-Shao, Gan-Cao, and SG-Tang were studied. To examine the cytotoxicity of these CHM formulas, MTT assay was performed on HEK-293 or SH-SY5Y cells after treatment with the tested formulas for $24 \mathrm{~h}$. As shown in Figure 1(a), Bai-Shao, Gan-Cao, and SG-Tang exhibited very low cytotoxicity in HEK-293 and SH-SY5Y cells.

Next, the amounts of active constituents, paeoniflorin and ammonium glycyrrhizinate, in these CHM formulas were analyzed by full-spectrum analytic HPLC. As shown in Figure 1(b), chromatographic patterns showed peaks at 230 and $250 \mathrm{~nm}$ corresponding to the retention time compatible with paeoniflorin and ammonium glycyrrhizinate, respectively. The amounts of active constituents in these CHM formulas $(0.5 \mathrm{~g} / \mathrm{ml})$ were $4.06 \%(42.25 \mathrm{mM})$ for paeoniflorin in Bai-Shao, 5.78\% (34.41 mM) for ammonium glycyrrhizinate in Gan-Cao, and 2.81\% (29.33 mM) for paeoniflorin and $2.43 \%(14.52 \mathrm{mM})$ for ammonium glycyrrhizinate in SG-Tang.

3.2. Radical-Scavenging Activity and Anti-Inflammatory Activity of the Tested Formulas. To evaluate the radicalscavenging activity of these CHM formulas, DPPH scavenging assay was conducted. As shown in Figure 2(a), Bai-Shao, Gan-Cao, and SG-Tang displayed free radical-scavenging activities with $\mathrm{EC}_{50}$ at $305 \mu \mathrm{g} / \mathrm{ml}, 794 \mu \mathrm{g} / \mathrm{ml}$, and $292 \mu \mathrm{g} / \mathrm{ml}$, respectively, indicating $\mathrm{SG}-\mathrm{Tang}$ has a greater radicalscavenging activity than Bai-Shao or Gan-Cao. The antiinflammatory responses of formulated CHMs were examined using RAW 264.7 cells, as LPS induced NO, TNF- $\alpha$, and IL-6 production in murine macrophages $[29,30]$. As shown in Figure 2(b), the exposure of RAW 264.7 cells to LPS resulted in a significant increase of NO, TNF- $\alpha$, IL- $1 \beta$, and IL- 6 after $24 \mathrm{~h}$ of incubation $(100 \%$ vs. $1 \sim 12 \%, p<0.001)$. The elevations in NO, TNF- $\alpha$, IL- $1 \beta$, and IL- 6 were reduced significantly in the presence of the nonsteroidal anti-inflammatory drug (NSAID) celecoxib (a selective cyclooxygenase (COX) inhibitor as a positive control) (NO: $39 \%, p<0.001$; TNF$\alpha: 23 \%, p=0.003$; IL-1 $\beta: 20 \%, p=0.001$; IL-6: $29 \%, p=$ $0.002)$. Similar inhibitory phenomena were observed in the cells treated with Gan-Cao and SG-Tang (NO: 72 16\%, $p=0.023 \sim<0.001$; TNF- $\alpha$ : 66 42\%, $p=0.044 \sim 0.001 ;$ IL- $1 \beta$ : $44 \sim 26 \%, \quad p=0.004 \sim<0.001 ; \quad$ IL-6: 51 20\%, $\quad p=0.003$ $\sim 0.001)$. Our results demonstrated that formulated CHMs Gan-Cao and SG-Tang possess anti-inflammatory effects by reducing production of inflammatory mediators.

3.3. Reduction of Tau Misfolding and Promotion of Neurite Outgrowth of the Tested Formulas. Previously, we generated a proaggregant $(\Delta \mathrm{K} 280)$ tau $_{\mathrm{RD}}$ cell model targeting tau misfolding [27]. Inhibition of tau aggregation may improve DsRed misfolding, leading to increased fluorescence in $\operatorname{tau}_{\mathrm{RD}}$-DsRed expressing cells. Utilizing the established Teton $\Delta \mathrm{K} 280 \operatorname{tau}_{\mathrm{RD}}$-DsRed 293 cells, Bai-Shao, Gan-Cao, and SG-Tang were tested for effects of reducing tau misfolding and antioxidation (Figure 3(a)). Fluorescent images of the cells were automatically recorded by a HCA system. As a positive control, Congo red $(5 \sim 20 \mu \mathrm{M})$ significantly increased the $\Delta \mathrm{K} 280 \mathrm{tau}_{\mathrm{RD}}$-DsRed fluorescence compared to no treatment $(113 \sim 127 \%$ vs. $100 \%, p=0.023 \sim 0.004)$. Significantly increased DsRed fluorescence was observed with Bai-Shao (109 117\% for 100 200 $\mu \mathrm{g} / \mathrm{ml}$ treatment, $p=0.028 \sim 0.023$ ), Gan-Cao (109 123\% for 50 200 $\mu \mathrm{g} / \mathrm{ml}$ treatment, $p=0.017$ $\sim 0.003)$, and SG-Tang $(108 \sim 130 \%$ for $50 \sim 200 \mu \mathrm{g} / \mathrm{ml}$ treatment, $p=0.003 \sim<0.001)$ compared to no treatment (Figure 3(b)). Representative fluorescent images of $\Delta \mathrm{K} 280$ $\mathrm{tau}_{\mathrm{RD}}$-DsRed cells untreated or treated with Congo red $(20 \mu \mathrm{M})$ or SG-Tang $(200 \mu \mathrm{g} / \mathrm{ml})$ are shown in Figure 3(c). The results indicated that Bai-Shao, Gan-Cao, and SG-Tang reduced tau misfolding in our tauopathy 293 cell model and SG-Tang demonstrated a better antiaggregation function than Bai-Shao or Gan-Cao.

Misfolded tau may increase the production of reactive oxygen species (ROS) [31]. To examine whether these CHM formulas display antioxidative effects, ROS level was evaluated in Tet-On $\Delta \mathrm{K} 280$ tau $_{\mathrm{RD}}$-DsRed 293 cells. As Figure $3(\mathrm{~d})$ shows, pretreatment with Congo red $(10 \mu \mathrm{M}$, a positive control) or formulas $(100 \mu \mathrm{g} / \mathrm{ml})$ significantly reversed the ROS level elevated by misfolded tau production compared to no treatment $(88 \sim 95 \%$ vs. $100 \%, p=0.045$ $\sim<0.001)$. These data showed the anti-oxidative effects of Bai-Shao, Gan-Cao, and SG-Tang, and SG-Tang possesses a greater anti-oxidative effect than Bai-Shao or Gan-Cao.

Since our study showed that SG-Tang has greater effects in free radical scavenging, antioxidation, and antiaggregation than Bai-Shao or Gan-Cao, we focused on SG-Tang treatment in subsequent experiments. The neuroprotective potential of SG-Tang was examined (Figure 4(a)). As Figure 4(b) shows, misfolded tau induction significantly reduced the length of neurites as compared to the absence of induction (93\% vs. $100 \%, p=0.030$ ) and $20 \mu \mathrm{M}$ Congo red (positive control) or $200 \mu \mathrm{g} / \mathrm{ml} \mathrm{SG-Tang} \mathrm{pretreatment} \mathrm{ameliorated}$ this negative effect ( $103 \%$ vs. 93\%, $p=0.041$ for Congo red; $101 \%$ vs. $93 \%, p=0.039$ for SG-Tang). Representative neurite outgrowth images uninduced (- Dox), untreated 

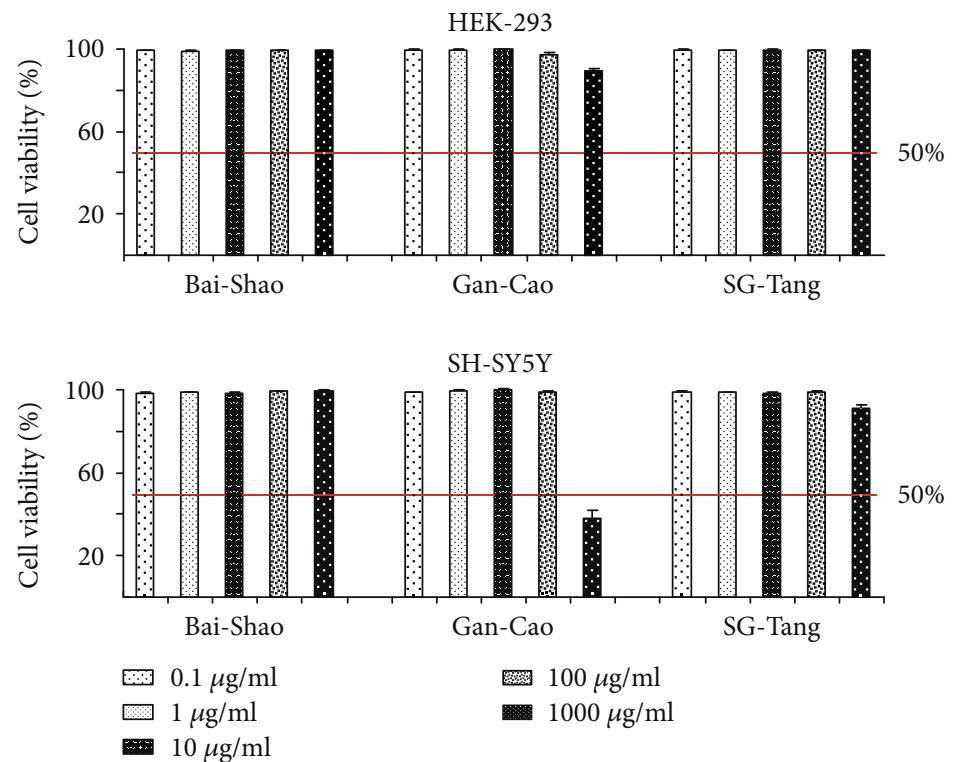

(a)
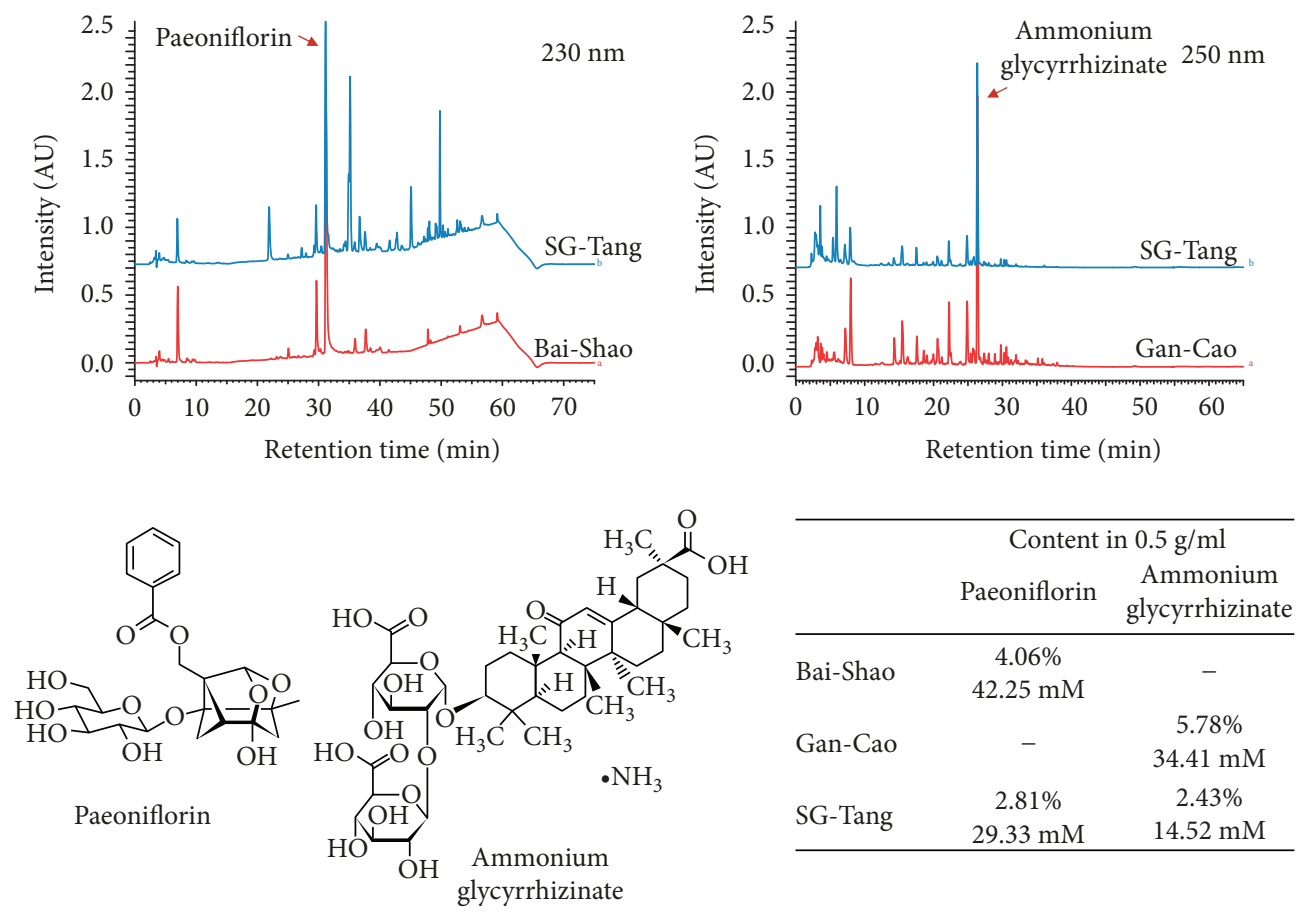

(b)

FIGURE 1: Cytotoxicity and chemical profiles of Bai-Shao, Gan-Cao, and SG-Tang. (a) MTT cell viability assay of HEK-293 and SH-SY5Y cells after treatment with Bai-Shao, Gan-Cao, and SG-Tang $(0.1 \sim 1000 \mu \mathrm{g} / \mathrm{ml})$ for $24 \mathrm{~h}$. To normalize, the relative viability of untreated cells was set as $100 \%$. The red line represents 50\% viability. (b) HPLC analysis of Bai-Shao, Gan-Cao, and SG-Tang. Chromatographic patterns (230 and $250 \mathrm{~nm}$ ) show peaks compatible with paeoniflorin and ammonium glycyrrhizinate. Also shown below are chemical structures of paeoniflorin and ammonium glycyrrhizinate and the relative amounts (in \% and $\mathrm{mM}$ ) of these molecules in Bai-Shao, Gan-Cao, and SG-Tang (0.5 g/ml).

(+ Dox), and after treatment with Congo red and SG-Tang are shown in Figure 4(c). Thus, SG-Tang exerts neuroprotective effect by rescuing the reduction of neurite outgrowth induced by tau misfolding.

3.4. Anti-Inflammatory Effects of SG-Tang in LPS-Stimulated $B V-2$ Microglia. In the brain, activated microglia release proinflammatory mediators such as $\mathrm{NO}$ and cytokines as a response to inflammation [32]. Thus, the anti-inflammatory effects of SG-Tang were determined using LPS-stimulated BV-2 microglia (Figure 5(a)). Figure 5(b) demonstrates that NO production of BV-2 cells significantly increased by LPS stimulation $(33.9 \mu \mathrm{M}$ vs. $4.8 \mu \mathrm{M}, p<0.001)$ and pretreatment of $100 \sim 500 \mu \mathrm{g} / \mathrm{ml} \mathrm{SG-Tang}$ for $8 \sim 24 \mathrm{~h}$ significantly reduced 


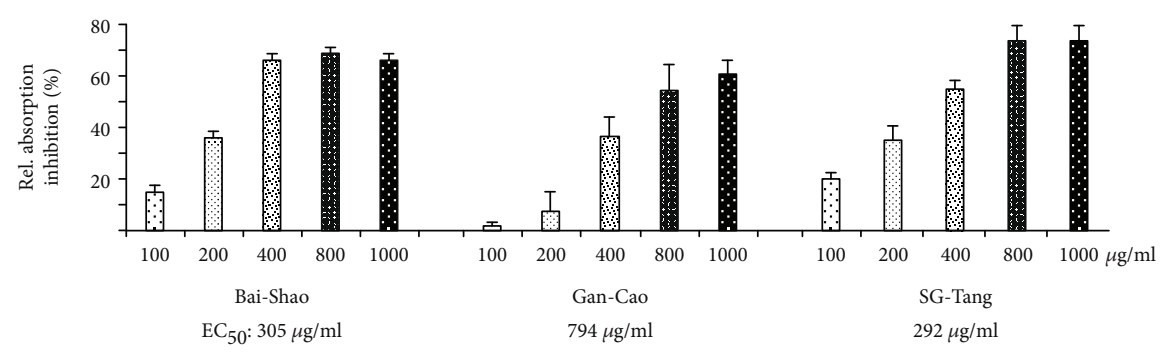

(a)

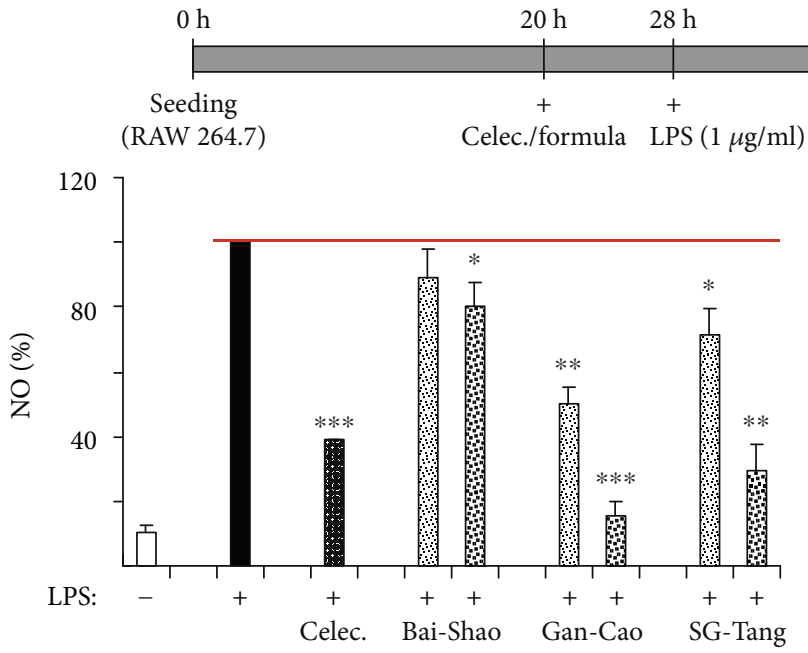

$48 \mathrm{~h}$
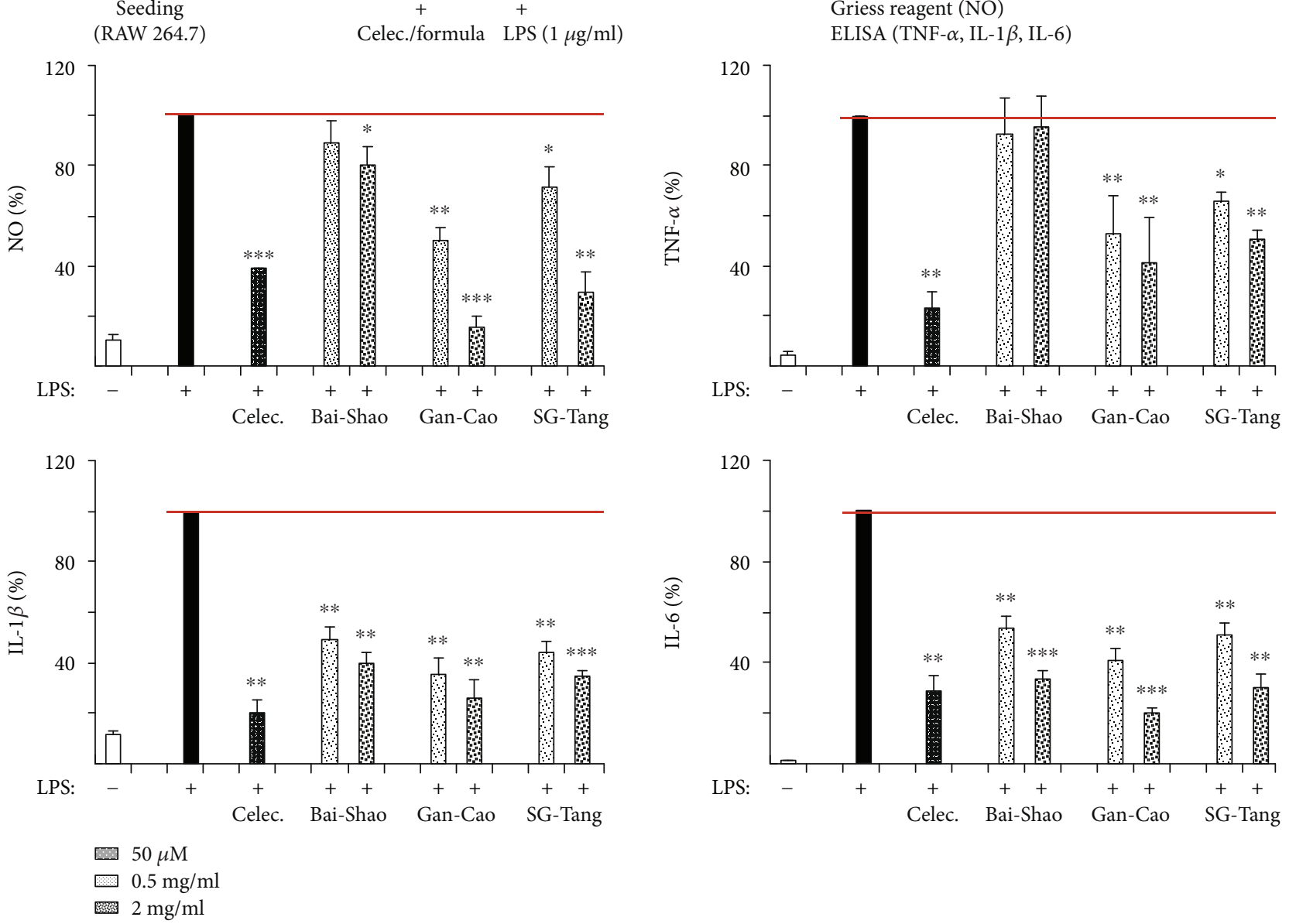

(b)

FIGURE 2: Antioxidative and anti-inflammatory activities of Bai-Shao, Gan-Cao, and SG-Tang. (a) DPPH radical-scavenging activities of the tested CHM formulas $(100 \sim 1000 \mu \mathrm{g} / \mathrm{ml})$. The $\mathrm{EC}_{50}$ of each formula is shown under the columns. (b) Anti-inflammatory activities of the tested formulas on RAW 264.7 macrophages. Cells $\left(10^{6}\right)$ were pretreated with formulas $(0.5 \sim 2 \mathrm{mg} / \mathrm{ml})$ or compound celecoxib $($ Celec., $50 \mu \mathrm{M})$ as a positive control for $8 \mathrm{~h}$, and LPS $(1 \mu \mathrm{g} / \mathrm{ml})$ was applied to induce inflammation. After $20 \mathrm{~h}$, the levels of NO (assessed by Griess reagent), TNF- $\alpha$, IL-1 $\beta$, and IL-6 (assessed by ELISA) released into cultured media were determined $(n=3)$. For normalization, the relative NO, TNF- $\alpha$, IL-1 $\beta$, and IL-6 levels of LPS-treated cells were set as $100 \% .{ }^{*} p<0.05,{ }^{* *} p<0.01$, and ${ }^{* * *} p<0.001$, celecoxib/formulas treated vs. untreated cells.

NO production $(100 \mu \mathrm{g} / \mathrm{ml}$ for $8 \mathrm{~h}: 23.7 \mu \mathrm{M}, p=0.008$; $500 \mu \mathrm{g} / \mathrm{ml}$ for $8 \mathrm{~h}: 19.4 \mu \mathrm{M}, p=0.002 ; 100 \mu \mathrm{g} / \mathrm{ml}$ for $24 \mathrm{~h}$ : $17.5 \mu \mathrm{M}, p=0.001 ; 500 \mu \mathrm{g} / \mathrm{ml}$ for $24 \mathrm{~h}: 12.2 \mu \mathrm{M}, p=0.002$ ).
The results indicate that SG-Tang displayed antiinflammatory effects by reducing NO production in microglia. We then applied LPS and IFN- $\gamma$ to BV-2 cells for $24 \mathrm{~h}$ for 


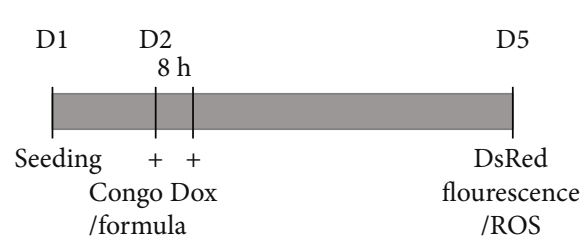

(a)
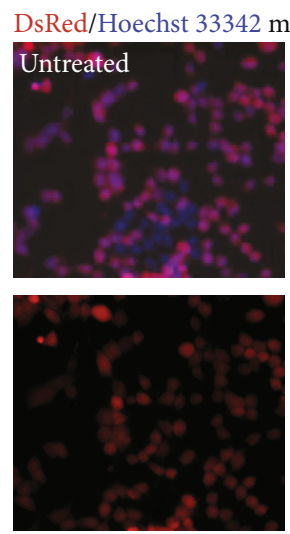

DsRed alone

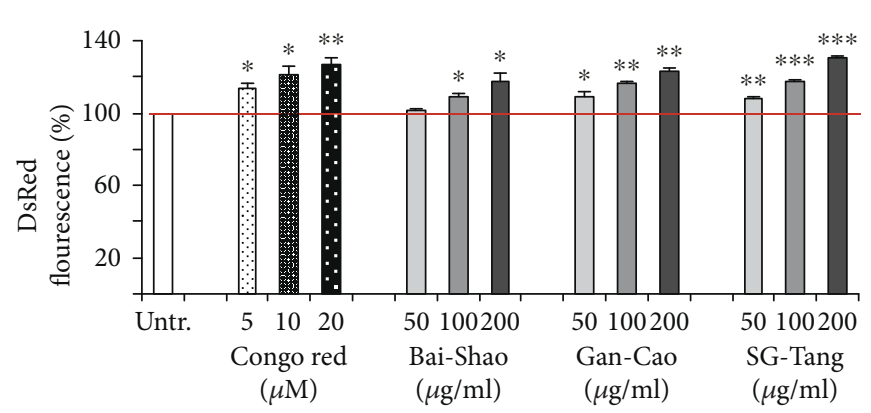

(b)
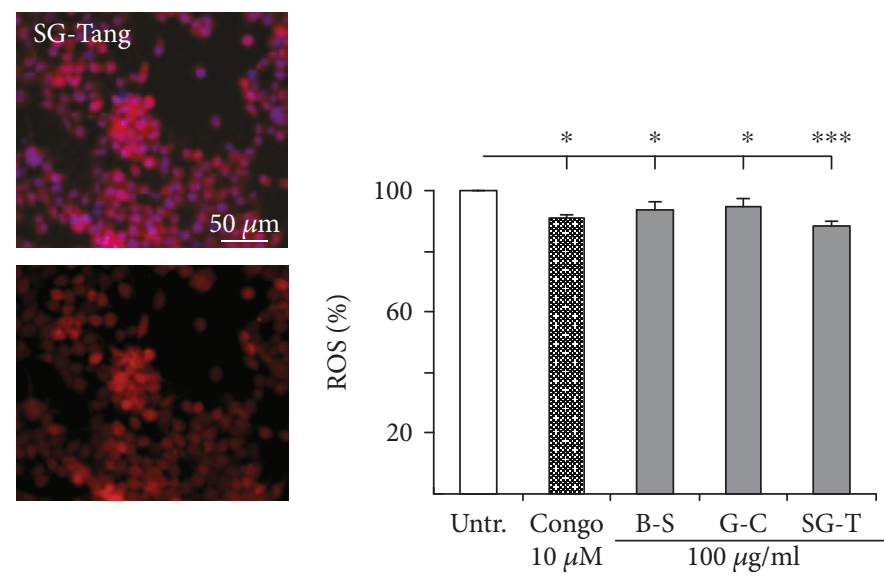

(d)

FIgUre 3: The effects of Bai-Shao, Gan-Cao, and SG-Tang on tau misfolding and ROS production in Tet-on $\Delta$ K280 tau RD $^{-D s R e d ~} 293$ cells. (a) Experiment flow chart. $\Delta \mathrm{K} 280 \mathrm{tau}_{\mathrm{RD}}$-DsRed 293 cells were pretreated with the tested formulas or Congo red (Congo, as a positive control) for $8 \mathrm{~h}$ before misfolded tau induction by doxycycline (Dox, $1 \mu \mathrm{g} / \mathrm{ml}$ ) for three days. (b) DsRed fluorescence analysis with Congo red (5 20 $\mu \mathrm{M}$ ) or the Chinese medicine formulas Bai-Shao, Gan-Cao, and SG-Tang $(50 \sim 200 \mu \mathrm{g} / \mathrm{ml})$ treatment $(n=3)$. The relative DsRed fluorescence of untreated cells is normalized (100\%). ${ }^{*} p<0.05,{ }^{* *} p<0.01$, and ${ }^{* * *} p<0.001$, treated vs. untreated cells. (c) Representative microscopy images (upper row: merged DsRed and Hoechst 33342 signals; low row: DsRed signal alone) of $\Delta \mathrm{K} 280$ tau $\mathrm{RD}^{-D s R e d} 293$ cells untreated or treated with Congo red $(20 \mu \mathrm{M})$ or SG-Tang $(200 \mu \mathrm{g} / \mathrm{ml})$. (d) ROS assay of $\Delta \mathrm{K} 280$ tau $_{\mathrm{RD}}$-DsRed 293 cells untreated or treated with Congo red $(10 \mu \mathrm{M})$ or the tested formulas Bai-Shao (B-S), Gan-Cao (G-C), and SG-Tang (SG-T) $(100 \mu \mathrm{g} / \mathrm{ml})(n=3)$. The relative ROS of untreated cells was normalized as $100 \% .{ }^{*} p<0.05$ and ${ }^{* * *} p<0.001$, treated vs. untreated cells.

conditioned medium (CM) collection (Figure 5(b)). The resting BV-2 microglia showed a ramified morphology but more extended processes with elongated morphology were observed after LPS/IFN- $\gamma$ treatment for $24 \mathrm{~h}$ (Figure 5(d)). As shown in Figures 5(e) and 5(f), elevated Iba1 (induction of brown adipocytes 1 , a microglial marker) expression in inflamed BV -2 cells ( $100 \%$ vs. $240 \%, p=0.042$ ) and increased release of NO, TNF- $\alpha$, IL- $1 \beta$, and IL- 6 in BV-2 CM (NO: $0.5 \mu \mathrm{M}$ vs. $49.6 \mu \mathrm{M}, p=0.001$; TNF- $\alpha: 0.9 \mathrm{ng} / \mathrm{ml}$ vs. $28.1 \mathrm{ng} /$ $\mathrm{ml}, p=0.002$; IL- $1 \beta: 2.9 \mathrm{pg} / \mathrm{ml}$ vs. $8.9 \mathrm{pg} / \mathrm{ml}, p<0.001$; IL-6: $0 \mathrm{ng} / \mathrm{ml}$ vs. $33.6 \mathrm{ng} / \mathrm{ml}, p=0.021)$ were confirmed. The collected CM was then used to provide inflammatory mediators to $\Delta \mathrm{K} 280$ tau $_{\mathrm{RD}}$-DsRed SH-SY5Y cells.

3.5. Effects of SG-Tang on BV-2 Conditioned MediumInflamed $\Delta K 280$ tau $_{R D}-$ DsRed SH-SY5Y Cells. Undifferentiated (without retinoic acid, - RA) or differentiated (with retinoic acid, + RA) $\Delta \mathrm{K} 280 \mathrm{tau}_{\mathrm{RD}}$-DsRed SH-SY5Y cells were pretreated with SG-Tang $(200 \mu \mathrm{g} / \mathrm{ml})$ for $8 \mathrm{~h}$ before misfolded tau induction and then BV-2 CM was added to provoke inflammatory damage on SH-SY5Y cells for two days (Figure 6(a)). Figure 6(b) shows that misfolded tau induction reduced the viability of $\Delta \mathrm{K} 280 \mathrm{tau}_{\mathrm{RD}}$-DsRed SHSY5Y cells ( - RA: $91 \%$ vs. $100 \%, p=0.012 ;+$ RA: $90 \%$ vs. $100 \%, p=0.035)$ and application of SG-Tang rescued the decreased cell viability caused by misfolded tau induction and BV-2 CM addition (- RA: $122 \%$ vs. $88 \%, p=0.015$; + RA: $122 \%$ vs. $91 \%, p=0.014)$. Thus, the reduced viability of inflamed $\Delta \mathrm{K} 280 \mathrm{tau}_{\mathrm{RD}}$-DsRed SH-SY5Y cells was not influenced by retinoic acid.

Differentiated SH-SY5Y cells expressing $\Delta \mathrm{K} 280 \mathrm{tau}_{\mathrm{RD}^{-}}$ DsRed were further evaluated on day 8 for $\mathrm{LDH}$ release, neurite outgrowth, and tau phosphorylation (Figure 6(c)). Both addition of Dox (118\% vs. $100 \%, p=0.019)$ and BV-2 CM (184\% vs. $118 \%, p<0.001)$ increased the $\mathrm{LDH}$ release of $\Delta \mathrm{K} 280 \mathrm{tau}_{\mathrm{RD}}$-DsRed SH-SY5Y cells and application of SG-Tang attenuated the LDH release (156\% vs. $184 \%, p=$ 0.010 ) (Figure 6(d)). Misfolded tau induction significantly reduced the length of neurites compared to the uninduced cells ( $94 \%$ vs. $100 \%, p=0.005)$, and addition of BV-2 CM 


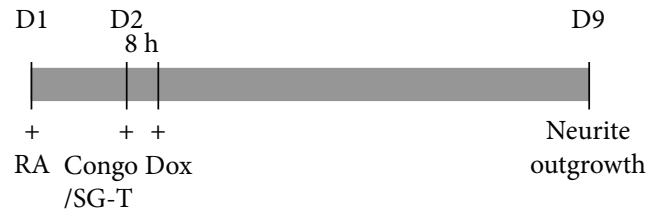

(a)
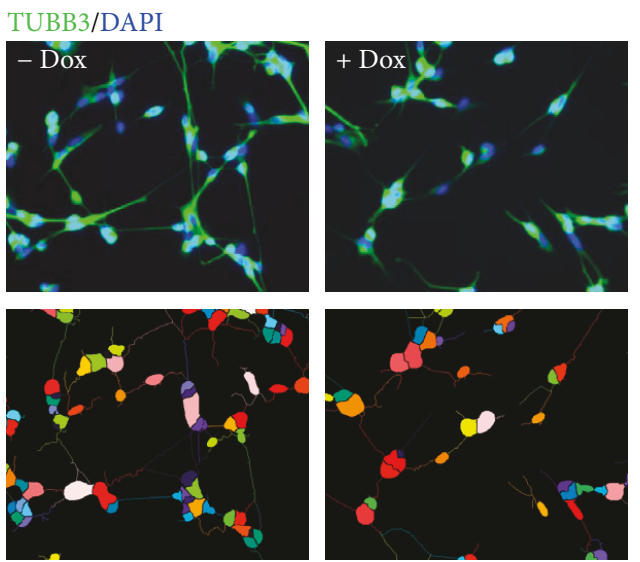

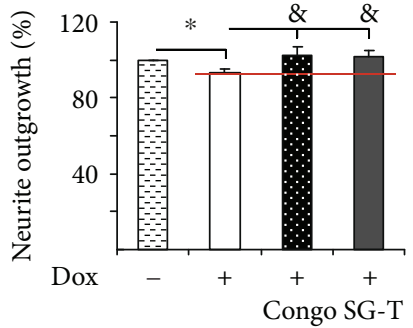

(b)
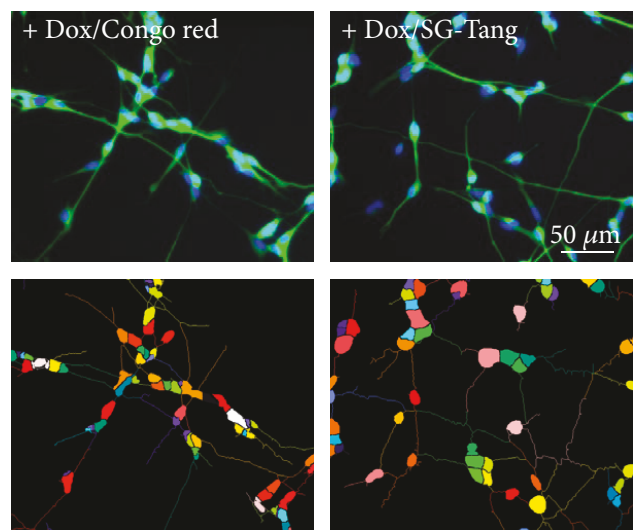

(c)

FIgURE 4: The effects of Bai-Shao, Gan-Cao and SG-Tang on neurite outgrowth in Tet-on $\Delta \mathrm{K} 280$ tau $_{\mathrm{RD}}$-DsRed SH-SY5Y cells. (a) Experiment flow chart. $\triangle \mathrm{K} 280 \mathrm{tau}_{\mathrm{RD}}$-DsRed SH-SY5Y cells were seeded in 24 -well $\left(3 \times 10^{4} /\right.$ well) plate with all trans retinoic acid (RA, $10 \mu \mathrm{M})$. On day 2 , cells were treated with Congo red $(20 \mu \mathrm{M})$ or SG-Tang $(200 \mu \mathrm{g} / \mathrm{ml})$ for $8 \mathrm{~h}$, induced tau $\mathrm{RD}^{-D_{\text {DRed }}}$ expression with doxycycline (Dox, $1 \mu \mathrm{g} / \mathrm{ml})$, and neurite outgrowth assayed on day 9. (b) Neurite outgrowth assay $(n=3)$ with Congo red or SG-Tang (SG-T) treatment. To normalize, the relative neurite outgrowth of untreated cells is set as $100 \%{ }^{*} p<0.05$, induced vs. un-induced cells; $\&_{p}<0.05$, treated vs. untreated cells. (c) Representative microscopy images of neuronally differentiated $\Delta \mathrm{K} 280$ tau $\mathrm{RD}^{-\mathrm{D}} \mathrm{DRed}$ SH-SY5Y cells uninduced (- Dox), untreated (+ Dox), and after treatment with Congo red (+ Dox/Congo red) or SG-Tang (+ Dox/SG-Tang). Neurites were stained with TUBB3 (neuronal class III $\beta$-tubulin, green) antibody. Nuclei were detected using (DAPI, blue). Upper row, merged TUBB3 and DAPI signals; lower row, images of the neurites and the body of individual cells being outlined by the same color for outgrowth quantification.

aggravated this condition ( $88 \%$ vs. $94 \%, p<0.001)$. Pretreatment of SG-Tang resulted in significant increase of neurite outgrowth ( $98 \%$ vs. $88 \%, p=0.004$ ) (Figure 6(e)). Representative images of neurite outgrowth of the above cells are shown in Figure 6(f).

The abnormal hyperphosphorylation of tau plays a role in the molecular pathogenesis of $\mathrm{AD}$ and other tauopathies. Therefore, the amount of phosphorylated tau was examined and Western blot showed that misfolded tau induction increased tau phosphorylation at residue Ser202, Thr231, and Ser396 compared to uninduced cells (Ser202: 130\% vs. $100 \%, p=0.020$; Thr231: $119 \%$ vs. $100 \%, p=0.016$; Ser396: $127 \%$ vs. $100 \%, p=0.012$ ). Although addition of BV-2 CM in misfolded tau-expressing cells did not cause further increase of tau phosphorylation at Ser202, Thr231, and Ser396, pretreatment of SG-Tang could reverse abnormal tau hyperphosphorylation at Ser202 (76\% vs. 107\%, $p=$ 0.022 ) and Thr231 (79\% vs. $122 \%, p=0.021$ ) (Figure $6(\mathrm{~g})$ ). Our results demonstrate that SG-Tang could protect cells from cell death, increase neurite outgrowth, and reduce hyperphosphorylation of tau in inflamed misfolded tauexpressing $\Delta \mathrm{K} 280$ tau $_{\mathrm{RD}}$-DsRed cells.
3.6. Identification of SG-Tang Targets by Human Apoptosis Antibody Array. TNF- $\alpha$ has been long considered as an effecter of inflammation-induced cell death. It has been shown that TNF- $\alpha$ binds to receptor TNFR1 to permit the release of silencer of death domain (SODD) and the recruitment of intracellular death signaling inducing signaling complex (DISC) proteins, including TNFR-associated death domain protein (TRADD) and Fas-associated protein with death domain (FADD), which then activates caspase 8 leading to apoptosis [33]. Caspase 8 is also a key mediator of inflammation and processing of pro-IL- $1 \beta$ to IL- $1 \beta$ [34]. Since we have found SG-Tang decreased TNF- $\alpha$ and IL- $1 \beta$ in $\mathrm{CM}$ of BV-2, we proposed that SG-Tang may also act on the inflammation-induced cell death. To elucidate the molecular mechanisms underlying the rescue from inflammationinduced cell death by SG-Tang, proteins from uninduced (- Dox), induced (+ Dox), inflamed (+ Dox/CM), and SGTang-pretreated inflamed (+ Dox/CM/SG-Tang) $\Delta \mathrm{K} 280$ $\operatorname{tau}_{\mathrm{RD}}$-DsRed SH-SY5Y cells were examined by using human apoptosis array to evaluate expression levels of 43 apoptosisrelated proteins (Figure $7(\mathrm{a})$ ). Among these targets, expression of proapoptotic Bcl2-associated agonist of cell death 


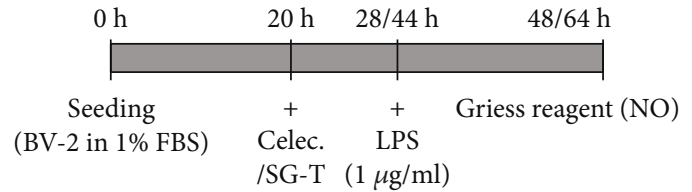

/SG-T $(1 \mu \mathrm{g} / \mathrm{ml})$

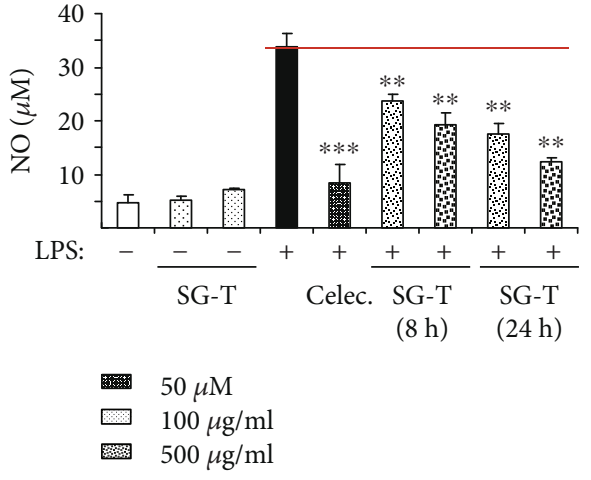

(b)
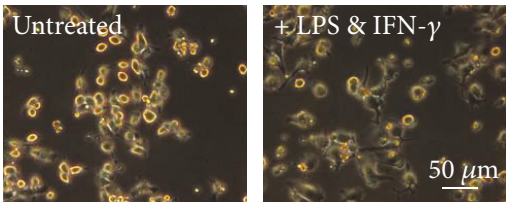

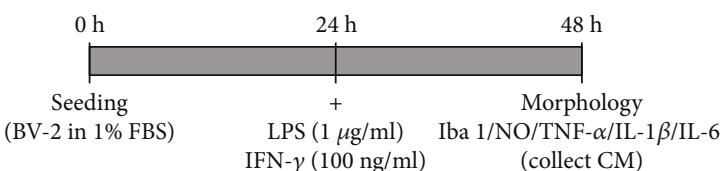

(c)

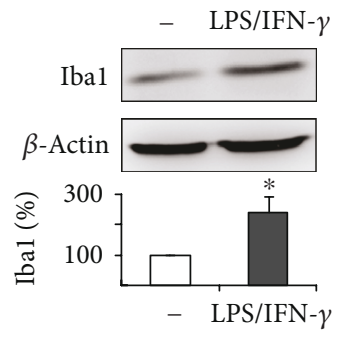

(e)
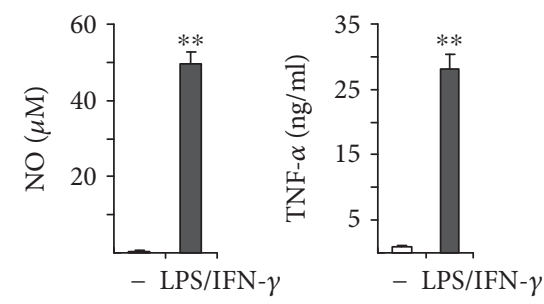

(d)
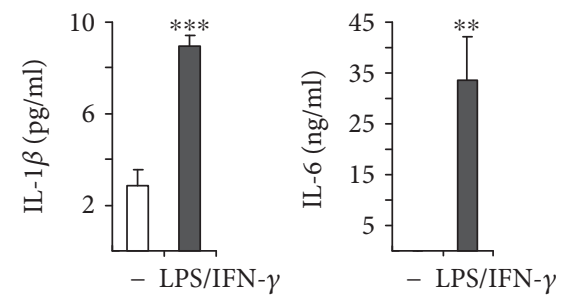

(f)

Figure 5: Anti-inflammatory effects of SG-Tang and BV-2 conditioned medium preparation. (a) Experiment flow chart for LPS stimulation. BV-2 cells were seeded in $1 \%$ fetal bovine serum (FBS) and pretreated with $50 \mu \mathrm{M}$ celecoxib (Celec.) for $8 \mathrm{~h}$ or $100 \sim 500 \mu \mathrm{g} / \mathrm{ml} \mathrm{SG-Tang}$ (SG-T) $8 \sim 24 \mathrm{~h}$ followed by $1 \mu \mathrm{g} / \mathrm{ml}$ LPS stimulation $20 \mathrm{~h}$. NO level was evaluated with Griess reagent. (b) Anti-inflammatory effect of celecoxib (Celec.) and SG-Tang (SG-T) on BV-2 cells $(n=3)$. ${ }^{* *} p<0.01$ and ${ }^{* * *} p<0.001$, treated vs. untreated cells. (c) Experiment flow chart for LPS/IFN- $\gamma$ stimulation. For preparation of BV-2 conditioned medium (CM), BV-2 cells were seeded in Dulbecco's modified Eagle's medium (DMEM) with $1 \%$ FBS medium. Next day, cells were stimulated with a combination of LPS (1 $\mu \mathrm{g} / \mathrm{ml})$ and IFN- $\gamma(100 \mathrm{ng} / \mathrm{ml})$. After $24 \mathrm{~h}$ stimulation, the BV-2 CM was collected and examined for inflammation by morphology, Ibal Western blotting and NO/TNF- $\alpha /$ IL-1 $\beta /$ IL-6 determination. (d) Morphology of BV-2 cells. (e) Western blot analysis of Iba1 expression in inflamed BV-2 cells $(n=3)$. To normalize, Iba1 expression level in uninflamed cells was set as $100 \%$. ${ }^{*} p<0.05$, stimulated vs. unstimulated cells. (f) Secretion of NO, TNF- $\alpha$, IL- $1 \beta$, and IL- 6 in BV-2 CM. ${ }^{* *} p<0.01$ and ${ }^{* * *} p<0.001$, stimulated vs. unstimulated cells.

(BAD), BH3-interacting domain death agonist (BID), caspase 3 (CASP3), caspase 8 (CASP8) and cytochrome $c$, and somatic (CYCS) were apparently reduced by SG-Tang treatment (Table 1). Western blot analysis of BAD, BID, CASP8, and CYCS expression changes and caspase 3 activity assay further confirmed that pretreatment of SG-Tang could significantly decrease these identified targets (BAD: from $228 \%$ to $157 \%, p=0.023$; BID: from $139 \%$ to $110 \%, p=$ 0.038; CASP8: from $118 \%$ to $104 \%, p=0.024$; CYCS: from $163 \%$ to $96 \%, p=0.040$; caspase 3 activity: from $165 \%$ to $103 \%, p=0.005)$. Moreover, addition of SG-Tang improved $\Delta \mathrm{K} 280 \mathrm{tau}_{\mathrm{RD}}$-DsRed misfolding and enhanced soluble $\mathrm{tau}_{\mathrm{RD}}$-DsRed protein level in inflamed $\Delta \mathrm{K} 280 \mathrm{tau}_{\mathrm{RD}}$-DsRed SH-SY5Y cells (from $90 \%$ to $115 \%, p=0.004$ ) (Figure $7(b)$ ). Our results indicated that SG-Tang may protect inflamed
$\Delta \mathrm{K} 280$ tau $_{\mathrm{RD}}$-DsRed SH-SY5Y cells by inhibiting production of proapoptotic proteins.

\section{Discussion}

In this study, we demonstrated neuroprotection, antioxidative and anti-inflammatory effects of formulated CHM SGTang. Our results showed that SG-Tang displayed a greater antioxidative and antiaggregation effect than Bai-Shao and Gan-Cao and a stronger anti-inflammatory activity than Bai-Shao but similar to Gan-Cao (Figures 2 and 3). Moreover, SG-Tang showed neuroprotective effect of promoting neurite outgrowth probably by ameliorating tau misfolding and oxidative stress in our tauopathy model (Figures 3 and 4). The anti-inflammatory effects of SG-Tang were further 

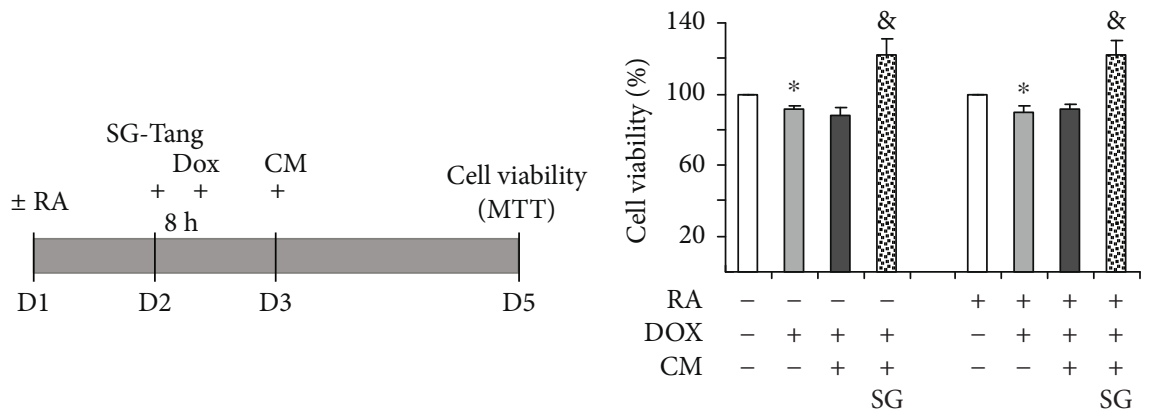

(a)

(b)

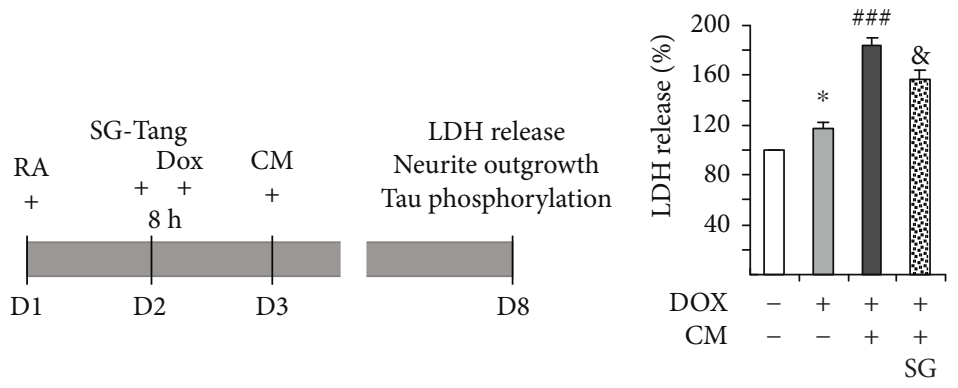

(c)

(d)

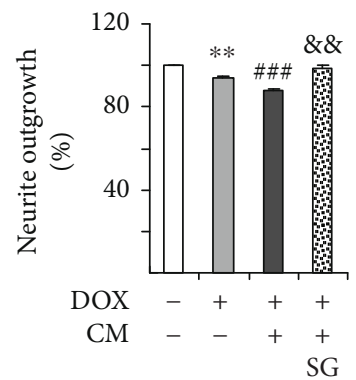

(e)
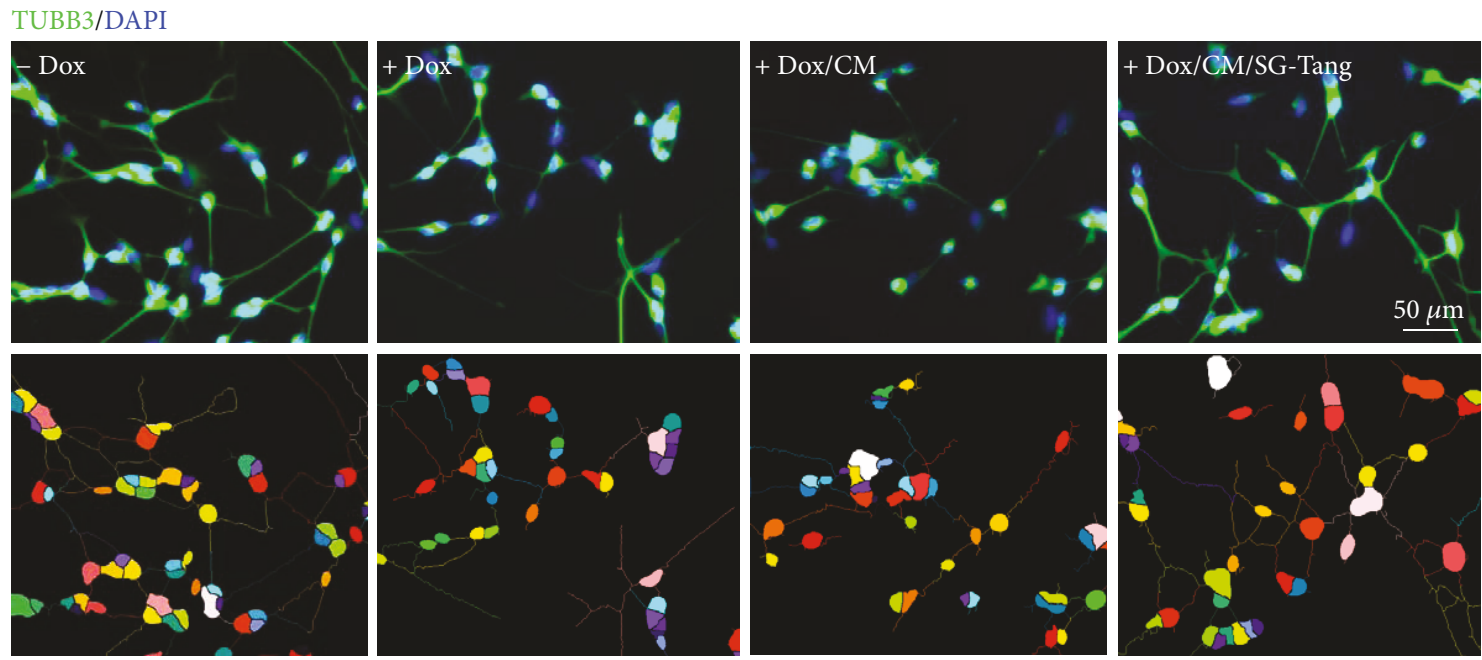

(f)

FIgURe 6: Continued. 


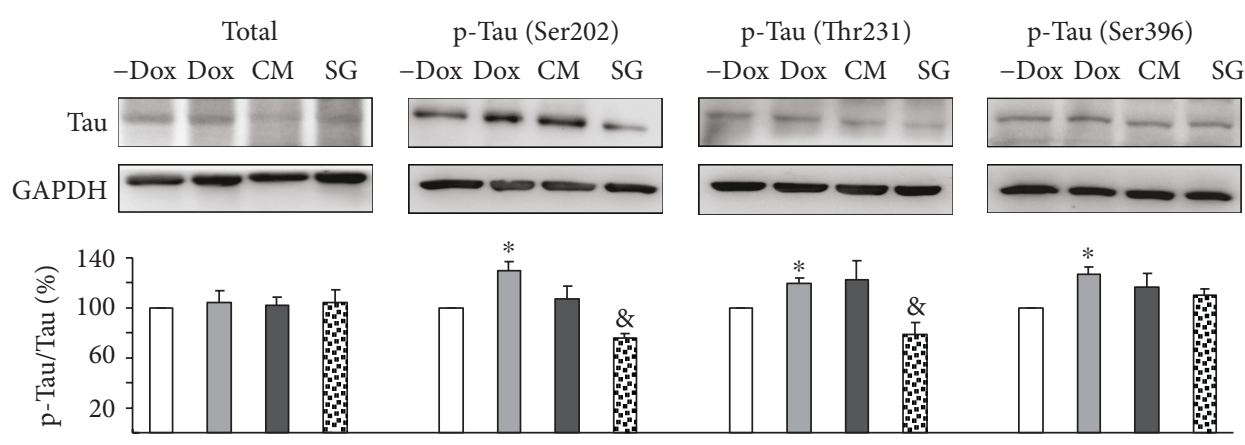

(g)

FIGURE 6: Neuroprotection of SG-Tang on $\Delta \mathrm{K} 280 \mathrm{tau}_{\mathrm{RD}}$-DsRed SH-SY5Y cells from BV-2 conditioned medium-induced cell death. (a) Experiment flow chart for cell viability assay. $\Delta \mathrm{K} 280 \mathrm{tau}_{\mathrm{RD}}$-DsRed SH-SY5Y cells were plated in media with/without retinoic acid $( \pm \mathrm{RA}$, $10 \mu \mathrm{M}$ ) on day 1 and pretreated with SG-Tang the next day for $8 \mathrm{~h}$, followed by doxycycline addition (Dox, $1 \mu \mathrm{g} / \mathrm{ml}$ ) to induce misfolded tau expression. On day 3, DMEM-F12 media was mixed with BV-2 CM and cell viability was assessed by MTT assay on day 5 . (b) Cell viability assay $\left({ }^{*} p<0.05,-\right.$ Dox vs. + Dox; ${ }^{8} p<0.05,+$ Dox/CM vs. + Dox/CM/SG-Tang-treated cells) $(n=3)$. (c) Experiment flow chart for $\mathrm{LDH}$ release, neurite outgrowth, and tau phosphorylation assays. RA ( $10 \mu \mathrm{M}$, present in cultures throughout) differentiated $\Delta \mathrm{K} 280$ $\operatorname{tau}_{\mathrm{RD}}$-DsRed SH-SY5Y cells were pretreated with SG-Tang $(200 \mu \mathrm{g} / \mathrm{ml})$ on day 2 for $8 \mathrm{~h}$, followed by inducing $\Delta \mathrm{K} 280$ tau $\mathrm{RD}^{-\mathrm{DsRed}}$ expression (+ Dox, $1 \mu \mathrm{g} / \mathrm{ml}$ ). On day 3, DMEM-F12 was mixed with BV-2 CM and added to the cells. After five days, media were collected for LDH release examination. In addition, cells were examined for neurite outgrowth and tau phosphorylation. (d) LDH assay $\left({ }^{*} p<0.05,-\right.$ Dox vs. + Dox; ${ }^{\# \#} p<0.001,+$ Dox vs. +Dox/CM; ${ }^{8} p<0.05,+$ Dox/CM vs. + Dox/CM/SG-Tang treated cells $)(n=3)$. (e) Neurite outgrowth assay $(n=3)$. To normalize, the relative neurite outgrowth of uninduced cells is set as $100 \%{ }^{* *} p<0.01,-$ Dox vs. + Dox; ${ }^{\# \# \#} p<0.001,+$ Dox vs. + Dox/CM; ${ }^{\& \&} p<0.01,+$ Dox/CM vs. + Dox/CM/SG-Tang-treated cells. (f) Representative microscopy images of differentiated $\triangle \mathrm{K} 280 \mathrm{tau}_{\mathrm{RD}}$-DsRed SH-SY5Y cells uninduced ( - Dox), induced (+ Dox), inflamed (+ Dox/CM), or treated with SG-Tang (+ Dox/CM/SG-Tang). Neurites were stained with TUBB3 (green) antibody. Nuclei were detected using DAPI (blue). Upper row, merged TUBB3 and DAPI signals; lower row, images of the neurites and the body of a cell being outlined by the same color for outgrowth quantification. (g) Western blot analysis of total and phosphorylated (Ser202, Thr231, and Ser396) tau (normalized to GAPDH internal control, $n=3) .{ }^{*} p<0.05$, - Dox vs. + Dox; ${ }^{*} p<0.05,+$ Dox/CM vs. + Dox/CM/SG-Tang-treated cells.

demonstrated by using LPS-stimulated BV-2 microglia (Figure 5). Targets identified from human apoptosis protein array indicate SG-Tang may suppress the expression levels of proapoptotic proteins in inflamed $\Delta \mathrm{K} 280 \mathrm{tau}_{\mathrm{RD}^{-}}$ DsRed SH-SY5Y cells and thus elevate the cell viability (Figures 6 and 7).

In human tauopathy, substantial activated microglia are found in regions of phosphorylated tau accumulation [35]. In tau P301S transgenic mice, prominent glial activation precedes tangle formation and the pattern of activated glia correlates closely with the distribution and density of NFTs [36]. As neuroinflammation is linked to the progression of tauopathy, anti-inflammatory strategy may be effective at reducing tau-related pathology. Indeed, FK506 attenuates tau pathology and increased lifespan in tau P301S mouse model [36]. Treatment of $3 \times \mathrm{Tg}$-AD mice with anti-inflammatory drug ibuprofen reduces tau phosphorylation and memory impairment [37]. Administration of potent anti-inflammatory minocycline reduces the development of disease-associated tau species in the htau mouse model [38] by reducing several inflammatory factors [39]. In the present study, we applied $\mathrm{BV}-2$ conditioned medium to proaggregant $\Delta \mathrm{K} 280$ tau $_{\mathrm{RD}^{-}}$ DsRed 293/SH-SY5Y cells to mimic neuroinflammation. The study results reveal that CHM formula SG-Tang displays neuroprotection by exerting anti-inflammatory and antiapoptotic activities.

Inflammation is a double-edged sword. Inflammatory response could lead to activation of immune system and elimination of pathogens thereby reducing further cell loss.
Although inflammation might be protective and beneficial to cells, prolonged or dysregulated inflammatory process could also result in production of neurotoxic factors that exacerbate neurodegenerative pathology and cause cell death [12]. Thus, a potential strategy for treating tauopathies is to intervene in microglial activation and neuroinflammation. NSAID has been commonly used as treatment of inflammation and known to be neuroprotective [40]. The mechanism of NSAID has been shown to inhibit the synthesis or activity of inflammatory mediators such as prostaglandin and COX isoforms 1 and 2. Although NSAID could effectively suppress the inflammatory symptoms, these agents may also induce significant side effects such as increased risk of thrombotic cardiovascular and cerebrovascular events [41]. Therefore, more safely, anti-inflammatory drugs need to be explored and developed.

There is a growing interest in natural compounds/products with anti-inflammatory activities which have long been used for treating inflammation-related diseases. In this study, SG-Tang used was formulated with Bai-Shao (P. lactiflora) and Gan-Cao (G. uralensis) and analyzed by HPLC using two main active constituents, paeoniflorin and ammonium glycyrrhizinate (Figure 1). Both paeoniflorin and glycyrrhizinic acid were demonstrated to be able to cross the bloodbrain barrier (BBB) in middle cerebral artery occlusion rats [42]. However, multiplicity of the components in P. lactiflora and $G$. uralensis contributes to the effects of antioxidation and anti-inflammation. In the root of P. lactiflora, a total of 40 components including 29 monoterpene glycosides, 


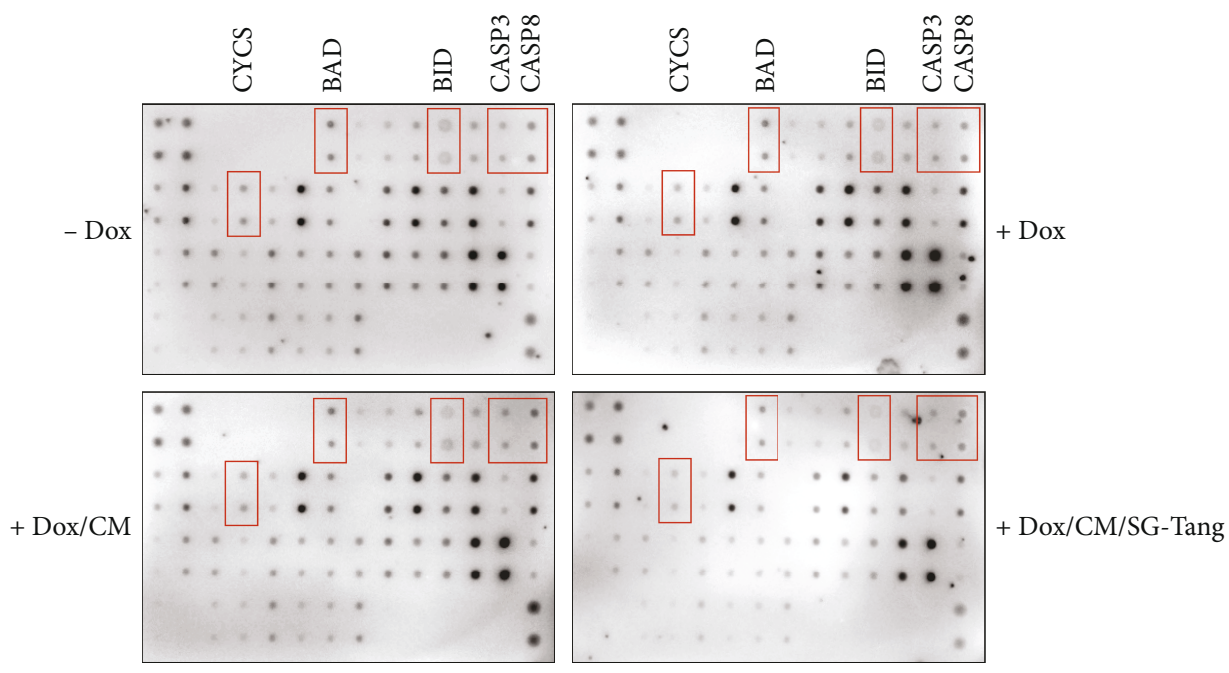

(a)
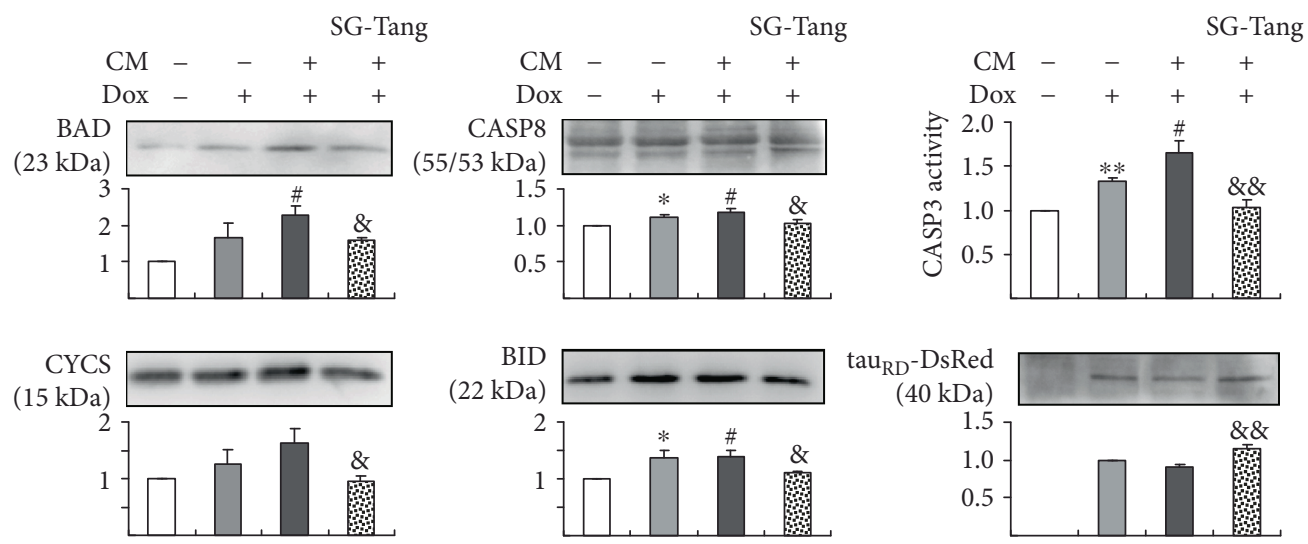

Tubulin

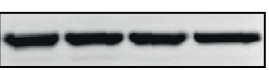

GAPDH

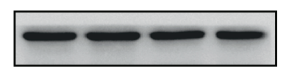

GAPDH

(b)

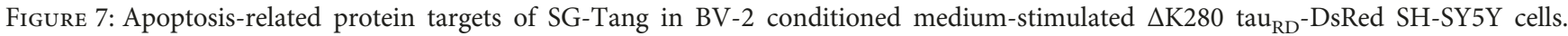
(a) Representative images of apoptosis antibody array of proteins collected from Figure 6(c). (b) Western blot analysis of BAD, CYCS, CASP8, BID, and tau $\mathrm{RD}$-DsRed protein levels (normalized to tubulin or GAPDH internal control, $n=3$ ) and caspase 3 activity assay from each sample. ${ }^{*} p<0.05$ and ${ }^{* *} p<0.01,-$ Dox vs. + Dox; ${ }^{\#} p<0.05,+$ Dox vs. + Dox/CM; ${ }^{\&} p<0.05$ and ${ }^{\& \&} p<0.01,+$ Dox/CM vs. + Dox/CM/SG-Tang-treated cells.

TABLe 1: Proteins identified by human apoptosis antibody array.

\begin{tabular}{lcccc}
\hline Gene symbol & $\begin{array}{c}\text { UniProt } \\
\text { accession number }\end{array}$ & Protein & $\begin{array}{c}\text { Fold change } \\
\text { (+ Dox/CM vs. - Dox) }\end{array}$ & $\begin{array}{c}\text { Fold change } \\
\text { (+ Dox/CM/SG-T vs. + Dox/CM) }\end{array}$ \\
\hline BAD & Q92934 & Bcl2-associated agonist of cell death & 1.16 & 0.63 \\
BID & P55957 & BH3-interacting domain death agonist & 1.33 & 0.41 \\
CASP3 & P42574 & Caspase 3 & 1.49 & 0.71 \\
CASP8 & Q14790 & Caspase 8 & 1.34 & 0.62 \\
CYCS & P99999 & Cytochrome c, somatic & 0.92 & 0.62 \\
\hline
\end{tabular}

8 galloyl glucoses, and 3 phenolic compounds were identified [43]. Among them, paeoniflorin, a monoterpene glycoside, is known to possess anti-inflammatory effect and has been applied to cerebral ischemic injury [44]. Paeoniflorin also exhibits neuroprotective effects via inhibiting neuroinflammation in APP/PS1 and in PS2 mutant mice $[45,46]$. Paeoniflorin and the isomer albiflorin attenuated neuropathic pain by inhibiting the activation of p38 MAPK pathway in spinal microglia and subsequent upregulated IL- $1 \beta$ and TNF- $\alpha$ [47]. Benzoylpaeoniflorin, another 
paeoniflorin-related glycoside in $P$. lactiflora root, protected primary rat cortical cells against $\mathrm{H}_{2} \mathrm{O}_{2}$-induced oxidative stress [48]. In addition to monoterpene glycosides, gallic acid, a phenolic compound in P. lactiflora root, displayed antioxidative effect by scavenging free radicals, inhibiting lipid peroxidation, and protecting against oxidative DNA damage [49]. Paeonol, another phenolic compound in $P$. lactiflora root, exerted neuroprotective effect in the model of ischemia through reducing proinflammatory receptors/ mediators [50].

The main bioactive components of $G$. uralensis are triterpene saponins and various types of flavonoids, including glycyrrhetinic acid, glycyrrhizic acid, liquiritigenin, isoliquiritigenin, liquiritin, and licochalcone A [51]. Glycyrrhizin and related compounds were found to show anti-inflammatory activity in vitro [52] and in vivo [53]. Although diammonium glycyrrhizinate rescues neurotoxicity in $\mathrm{A} \beta_{1-42^{-}}$ induced mice [54], its effect in tauopathy models is not known. Isoliquiritigenin, isoliquiritin, and liquiritigenin significantly suppressed iNOS, TNF- $\alpha$, and IL- 6 expression in IL-1 $\beta$-treated rat hepatocytes [55]. Interestingly, the purified glycyrrhiza polysaccharides increased the pinocytic activity, the production of NO, IL-1, IL-6, and IL-12 in macrophages of mice [56]. Glycyrrhetinic acid, liquiritigenin, isoliquiritigenin, and liquiritin were also found to be all potent NRF2 inducers [57]. Moreover, Calzia et al. has shown that polyphenolic phytochemicals displayed a potent antioxidant action by modulating the ectopic $\mathrm{F}_{0} \mathrm{~F}_{1}$-ATP synthase activity of the rod outer segments of the retina and prevented the induction of apoptosis [58]. Therefore, polyphenolic compounds from Bai-Shao and Gan-Cao may also exert antioxidative activities not only in but also outside of mitochondria. Given that multiple different compounds in both Bai-Shao and Gan-Cao are exerting effects on different pathways, the combination of Bai-Shao and Gan-Cao may thus have additive protection effects than each alone, which is supported by our study results.

The anti-inflammatory effect of Jakyakgamcho-tang, a formulated P. lactiflora and G. uralensis in Korea, has been shown by inhibiting the NF- $\kappa \mathrm{B}$ signaling pathway in keratinocytes [59]. Aberrant activation of NF- $\kappa \mathrm{B}$ signaling may lead to apoptosis and cell death [60]. We found that several proapoptotic proteins including BAD, BID, CASP3, CASP8, and CYCS were induced by misfolded tau expression and/ or caused by LPS/IFN- $\gamma$-stimulated BV2 microglia. BAD protein is a proapoptotic member of the Bcl-2 gene family involved in initiating apoptosis [61]. BID is also a proapoptotic protein which plays a role as a sentinel for protease-mediated death signals [62]. Caspases are well-studied important mediators of apoptosis. CYCS is known to be released from mitochondria into cytosol to stimulate cell apoptosis [63]. Administration of SG-Tang decreased the production of these proapoptotic proteins, indicating that SG-Tang may target on inhibiting proapoptotic proteins to protect neuron cells from inflammatory damage.

Finally, pretreatment of SG-Tang reversed abnormal hyperphosphorylation at tau Ser202 and Thr231 in inflamed misfolded tau-expressing SH-SY5Y cells (Figure 6). Tau function is regulated by phosphorylation at specific sites, and tau phosphorylation plays both physiological and pathological roles in the cells. Tau Ser199/202 and Thr205 were found to be locally phosphorylated along the nascent axon during axonogenesis [64]. Phosphorylation of tau Thr231 inhibited tau to bind and stabilize microtubules [65]. Both Ser202 and Thr231 are hyperphosphorylated in degenerating AD brain [66]. Among kinases that regulate tau Ser202 and Thr231 phosphorylation, cyclic AMP-dependent protein kinase (PKA) and cyclin-dependent kinase 2 (CDC2) might be the potential targets of SG-Tang, and SG-Tang treatment may result in activity suppression of these two kinases $[66,67]$. The exact mechanism for PKA or CDC2 regulation by SG-Tang remains to be determined in our future work.

\section{Conclusions}

Plant-derived natural medications have been used for centuries and becoming more popular because of their low side effects. Despite the fact that natural compounds are relatively safe, the complexity of natural products makes nutraceutical preparations difficult to be appropriately designed. In this study, we showed antioxidative and anti-inflammatory effects of SG-Tang as a potential agent for treatment or prevention of neuroinflammation-associated tauopathy. In future, studies of main active compounds paeoniflorin and ammonium glycyrrhizinate in SG-Tang, separately or in combination, in tauopathy cell model are warranted to provide a novel avenue for protection against tauopathy.

\section{Abbreviations}

AD: $\quad$ Alzheimer's disease

BAD: $\quad \mathrm{Bcl} 2$-associated agonist of cell death

BBB: $\quad$ Blood-brain barrier

BID: $\quad$ BH3-interacting domain death agonist

BSA: Bovine serum albumin

CASP3: Caspase 3

CASP8: $\quad$ Caspase 8

CDC2: Cyclin-dependent kinase 2

CHM: Chinese herbal medicine

CM: $\quad$ Conditioned medium

CNS: Central nervous system

COX: Cyclooxygenase

CYCS: Cytochrome c, somatic

DAPI: $\quad 4^{\prime}$-6-Diamidino-2-phenylindole

Dox: Doxycycline

DMEM: Dulbecco's modified Eagle's medium

DPPH: 1,1-Diphenyl-2-picrylhydrazyl

$\mathrm{EC}_{50}$ : Half maximal effective concentration

ELISA: Enzyme-linked immunosorbent assay

FBS: $\quad$ Fetal bovine serum

HCA: High-content analysis

HPLC: High-performance liquid chromatography

Iba1: Induction of brown adipocytes 1

$\mathrm{IC}_{50}$ : Half maximal inhibitory concentration

IFN: Interferon

IL: Interleukin

LDH: $\quad$ Lactate dehydrogenase

LPS: $\quad$ Lipopolysaccharide 
MTT: 3-(4,5-Dimethylthiazol-2-yl)-2,5-diphenyltetrazolium bromide

NO: $\quad$ Nitric oxide

NSAID: Nonsteroidal anti-inflammatory drug

PKA: $\quad$ Cyclic AMP-dependent protein kinase

ROS: $\quad$ Reactive oxygen species

SG-Tang: Shaoyao Gancao Tang

$\mathrm{tau}_{\mathrm{RD}}$ : Tau repeat domain

TNF: Tumor necrosis factor.

\section{Data Availability}

The data used to support the findings of this study are available from the corresponding author upon request.

\section{Conflicts of Interest}

The authors declare no conflicts of interest.

\section{Authors' Contributions}

Guey-Jen Lee-Chen and Chiung-Mei Chen designed the research and revised the paper. I-Cheng Chen performed the experiments, analyzed the data, and wrote the manuscript. Te-Hsien Lin conducted experiments and analyzed the data. Yu-Hsuan Hsieh and Chih-Ying Chao performed experiments and assisted in the technical work. Yih- $\mathrm{Ru} \mathrm{Wu}$ and Kuo-Hsuan Chang commented on the experiment design. Ming-Chung Lee provided CHM materials for this study. All authors approved the final version of the manuscript. I-Cheng Chen and Te-Hsien Lin contributed equally to this work.

\section{Acknowledgments}

This work was supported by the grants from the Ministry of Science and Technology (105-2325-B-003-001) and Chang Gung Memorial Hospital (CMRPG3F136, CMRPG3F16112, and CMRPG3G052). We thank the Molecular Imaging Core Facility of National Taiwan Normal University for the technical assistance.

\section{References}

[1] D. R. Williams, "Tauopathies: classification and clinical update on neurodegenerative diseases associated with microtubuleassociated protein tau," Internal Medicine Journal, vol. 36, no. 10 , pp. 652-660, 2006.

[2] G. Lee and C. J. Leugers, "Tau and tauopathies," Progress in Molecular Biology and Translational Science, vol. 107, pp. 263-293, 2012.

[3] R. L. Neve, P. Harris, K. S. Kosik, D. M. Kurnit, and T. A. Donlon, "Identification of cDNA clones for the human microtubule-associated protein tau and chromosomal localization of the genes for tau and microtubule-associated protein 2," Brain Research, vol. 387, no. 3, pp. 271-280, 1986.

[4] M. Hasegawa, M. J. Smith, and M. Goedert, "Tau proteins with FTDP-17 mutations have a reduced ability to promote microtubule assembly," FEBS Letters, vol. 437, no. 3, pp. 207210, 1998 .
[5] P. Nacharaju, J. Lewis, C. Easson et al., "Accelerated filament formation from tau protein with specific FTDP-17 missense mutations," FEBS Letters, vol. 447, no. 2-3, pp. 195-199, 1999.

[6] I. D'Souza, P. Poorkaj, M. Hong et al., "Missense and silent tau gene mutations cause frontotemporal dementia with parkinsonism-chromosome 17 type, by affecting multiple alternative RNA splicing regulatory elements," Proceedings of the National Academy of Sciences of the United States of America, vol. 96, no. 10, pp. 5598-5603, 1999.

[7] P. Rizzu, J. C. van Swieten, M. Joosse et al., "High prevalence of mutations in the microtubule-associated protein tau in a population study of frontotemporal dementia in the Netherlands," The American Journal of Human Genetics, vol. 64, no. 2, pp. 414-421, 1999.

[8] P. Momeni, A. Pittman, T. Lashley et al., "Clinical and pathological features of an Alzheimer's disease patient with the MAPT $\triangle$ K280 mutation," Neurobiology of Aging, vol. 30, no. 3, pp. 388-393, 2009.

[9] S. Barghorn, Q. Zheng-Fischhöfer, M. Ackmann et al., "Structure, microtubule interactions, and paired helical filament aggregation by tau mutants of frontotemporal dementias," Biochemistry, vol. 39, no. 38, pp. 11714-11721, 2000.

[10] V. Vogelsberg-Ragaglia, J. Bruce, C. Richter-Landsberg et al., "Distinct FTDP-17 missense mutations in tau produce tau aggregates and other pathological phenotypes in transfected CHO cells," Molecular Biology of the Cell, vol. 11, no. 12, pp. 4093-4104, 2000.

[11] M. von Bergen, S. Barghorn, L. Li et al., "Mutations of tau protein in frontotemporal dementia promote aggregation of paired helical filaments by enhancing local $\beta$-structure," The Journal of Biological Chemistry, vol. 276, no. 51, pp. 4816548174, 2001.

[12] P. J. Khandelwal, A. M. Herman, and C. E. H. Moussa, "Inflammation in the early stages of neurodegenerative pathology," Journal of Neuroimmunology, vol. 238, no. 1-2, pp. 1-11, 2011.

[13] P. L. DiPatre and B. B. Gelman, "Microglial cell activation in aging and Alzheimer disease: partial linkage with neurofibrillary tangle burden in the hippocampus," Journal of $\mathrm{Neu}$ ropathology and Experimental Neurology, vol. 56, no. 2, pp. 143-149, 1997.

[14] K. Ishizawa and D. W. Dickson, "Microglial activation parallels system degeneration in progressive supranuclear palsy and corticobasal degeneration," Journal of Neuropathology and Experimental Neurology, vol. 60, no. 6, pp. 647-657, 2001.

[15] M. Kitazawa, T. R. Yamasaki, and F. M. Laferla, "Microglia as a potential bridge between the amyloid $\beta$-peptide and tau," Annals of the New York Academy of Sciences, vol. 1035, no. 1, pp. 85-103, 2004.

[16] Y. Li, L. Liu, S. W. Barger, and W. S. T. Griffin, "Interleukin-1 mediates pathological effects of microglia on tau phosphorylation and on synaptophysin synthesis in cortical neurons through a p38-MAPK pathway," The Journal of Neuroscience, vol. 23, no. 5, pp. 1605-1611, 2003.

[17] K. Bhaskar, M. Konerth, O. N. Kokiko-Cochran, A. Cardona, R. M. Ransohoff, and B. T. Lamb, "Regulation of tau pathology by the microglial fractalkine receptor," Neuron, vol. 68 , no. 1 , pp. 19-31, 2010.

[18] M. Kitazawa, S. Oddo, T. R. Yamasaki, K. N. Green, and F. LaFerla, "Lipopolysaccharide-induced inflammation exacerbates tau pathology by a cyclin-dependent kinase 5-mediated 
pathway in a transgenic model of Alzheimer's disease," Journal of Neuroscience, vol. 25, no. 39, pp. 8843-8853, 2005.

[19] A. N. Nilson, K. C. English, J. E. Gerson et al., "Tau oligomers associate with inflammation in the brain and retina of tauopathy mice and in neurodegenerative diseases," Journal of Alzheimer's Disease, vol. 55, no. 3, pp. 1083-1099, 2017.

[20] P. D. Wes, F. A. Sayed, F. Bard, and L. Gan, "Targeting microglia for the treatment of Alzheimer's disease," Glia, vol. 64, no. 10, pp. 1710-1732, 2016.

[21] A. Ardura-Fabregat, E. W. G. M. Boddeke, A. Boza-Serrano et al., "Targeting neuroinflammation to treat Alzheimer's disease,” CNS Drugs, vol. 31, no. 12, pp. 1057-1082, 2017.

[22] J. Gao, Y. Inagaki, X. Li, N. Kokudo, and W. Tang, "Research progress on natural products from traditional Chinese medicine in treatment of Alzheimer's disease," Drug Discoveries \& Therapeutics, vol. 7, no. 2, pp. 46-57, 2013.

[23] Z. Y. Wang, J. G. Liu, H. Li, and H. M. Yang, "Pharmacological effects of active components of Chinese herbal medicine in the treatment of Alzheimer's disease: a review," The American Journal of Chinese Medicine, vol. 44, no. 08, pp. 1525-1541, 2016.

[24] T. Y. Wu, C. P. Chen, and T. R. Jinn, "Traditional Chinese medicines and Alzheimer's disease," Taiwanese Journal of Obstetrics \& Gynecology, vol. 50, no. 2, pp. 131-135, 2011.

[25] Y.Q.Zheng and W. Wei, "Total glucosides of paeony suppresses adjuvant arthritis in rats and intervenes cytokine-signaling between different types of synoviocytes," International Immunopharmacology, vol. 5, no. 10, pp. 1560-1573, 2005.

[26] T.-Y. Wu, T. O. Khor, C. L. L. Saw et al., "Anti-inflammatory/ anti-oxidative stress activities and differential regulation of Nrf2-mediated genes by non-polar fractions of tea Chrysanthemum zawadskii and licorice Glycyrrhiza uralensis," The AAPS Journal, vol. 13, no. 1, pp. 1-13, 2011.

[27] K.-H. Chang, I.-C. Chen, H.-Y. Lin et al., "The aqueous extract of Glycyrrhiza inflata can upregulate unfolded protein response-mediated chaperones to reduce tau misfolding in cell models of Alzheimer's disease," Drug Design, Development and Therapy, vol. 10, pp. 885-896, 2016.

[28] D. Brown, A. Tamas, D. Reglodi, and Y. Tizabi, "PACAP protects against inflammatory-mediated toxicity in dopaminergic SH-SY5Y cells: implication for Parkinson's disease," Neurotoxicity Research, vol. 26, no. 3, pp. 230-239, 2014.

[29] Y. C. Park, C. H. Lee, H. S. Kang, H. T. Chung, and H. D. Kim, "Wortmannin, a specific inhibitor of phosphatidylinositol-3kinase, enhances LPS-induced NO production from murine peritoneal macrophages," Biochemical and Biophysical Research Communications, vol. 240, no. 3, pp. 692-696, 1997.

[30] H. Fang, R. A. Pengal, X. Cao et al., "Lipopolysaccharideinduced macrophage inflammatory response is regulated by SHIP," Journal of Immunology, vol. 173, no. 1, pp. 360-366, 2004.

[31] M. Cente, P. Filipcik, M. Pevalova, and M. Novak, "Expression of a truncated tau protein induces oxidative stress in a rodent model of tauopathy," The European Journal of Neuroscience, vol. 24, no. 4, pp. 1085-1090, 2006.

[32] P. L. McGeer, T. Kawamata, D. G. Walker, H. Akiyama, I. Tooyama, and E. G. McGeer, "Microglia in degenerative neurological disease," Glia, vol. 7, no. 1, pp. 84-92, 1993.

[33] L. M. Sedger and M. F. McDermott, "TNF and TNF-receptors: from mediators of cell death and inflammation to therapeutic giants - past, present and future," Cytokine \& Growth Factor Reviews, vol. 25, no. 4, pp. 453-472, 2014.

[34] T. P. Monie and C. E. Bryant, "Caspase- 8 functions as a key mediator of inflammation and pro-IL- $1 \beta$ processing via both canonical and non-canonical pathways," Immunological Reviews, vol. 265, no. 1, pp. 181-193, 2015.

[35] A. Sasaki, T. Kawarabayashi, T. Murakami et al., "Microglial activation in brain lesions with tau deposits: comparison of human tauopathies and tau transgenic mice TgTauP301L," Brain Research, vol. 1214, pp. 159-168, 2008.

[36] Y. Yoshiyama, M. Higuchi, B. Zhang et al., "Synapse loss and microglial activation precede tangles in a P301S tauopathy mouse model," Neuron, vol. 53, no. 3, pp. 337-351, 2007.

[37] A. C. McKee, I. Carreras, L. Hossain et al., "Ibuprofen reduces $\mathrm{A} \beta$, hyperphosphorylated tau and memory deficits in Alzheimer mice," Brain Research, vol. 1207, pp. 225-236, 2008.

[38] W. Noble, C. Garwood, J. Stephenson, A. M. Kinsey, D. P. Hanger, and B. H. Anderton, "Minocycline reduces the development of abnormal tau species in models of Alzheimer's disease," The FASEB Journal, vol. 23, no. 3, pp. 739-750, 2009.

[39] C. J. Garwood, J. D. Cooper, D. P. Hanger, and W. Noble, "Anti-inflammatory impact of minocycline in a mouse model of tauopathy," Frontiers in Psychiatry, vol. 1, p. 136, 2010.

[40] M. A. Ajmone-Cat, A. Bernardo, A. Greco, and L. Minghetti, "Non-steroidal anti-inflammatory drugs and brain inflammation: effects on microglial functions," Pharmaceuticals (Basel), vol. 3, no. 6, pp. 1949-1965, 2010.

[41] J. C. Maroon, J. W. Bost, and A. Maroon, "Natural antiinflammatory agents for pain relief," Surgical Neurology International, vol. 1, no. 1, p. 80, 2010.

[42] H. Li, M. Ye, Y. Zhang et al., "Blood-brain barrier permeability of Gualou Guizhi granules and neuroprotective effects in ischemia/reperfusion injury," Molecular Medicine Reports, vol. 12, no. 1, pp. 1272-1278, 2015.

[43] S. L. Li, J. Z. Song, F. F. K. Choi et al., "Chemical profiling of Radix Paeoniae evaluated by ultra-performance liquid chromatography/photo-diode-array/quadrupole time-of-flight mass spectrometry," Journal of Pharmaceutical and Biomedical Analysis, vol. 49, no. 2, pp. 253-266, 2009.

[44] Y. Zhang, H. Li, M. Huang et al., "Paeoniflorin, a monoterpene glycoside, protects the brain from cerebral ischemic injury via inhibition of apoptosis," The American Journal of Chinese Medicine, vol. 43, no. 03, pp. 543-557, 2015.

[45] H. R. Zhang, J. H. Peng, X. B. Cheng, B. Z. Shi, M. Y. Zhang, and R. X. Xu, "Paeoniflorin atttenuates amyloidogenesis and the inflammatory responses in a transgenic mouse model of Alzheimer's disease," Neurochemical Research, vol. 40, no. 8, pp. 1583-1592, 2015.

[46] X. Gu, Z. Cai, M. Cai et al., "Protective effect of paeoniflorin on inflammation and apoptosis in the cerebral cortex of a transgenic mouse model of Alzheimer's disease," Molecular Medicine Reports, vol. 13, no. 3, pp. 2247-2252, 2016.

[47] J. Zhou, L. Wang, J. Wang et al., "Paeoniflorin and albiflorin attenuate neuropathic pain via MAPK pathway in chronic constriction injury rats," Evidence-Based Complementary and Alternative Medicine, vol. 2016, Article ID 8082753, 11 pages, 2016.

[48] S. H. Kim, M. K. Lee, K. Y. Lee, S. H. Sung, J. Kim, and Y. C. Kim, "Chemical constituents isolated from Paeonia lactiflora roots and their neuroprotective activity against oxidative stress 
in vitro," Journal of Enzyme Inhibition and Medicinal Chemistry, vol. 24, no. 5, pp. 1138-1140, 2009.

[49] S. C. Lee, Y. S. Kwon, K. H. Son, H. P. Kim, and M. Y. Heo, "Antioxidative constituents from Paeonia lactiflora," Archives of Pharmacal Research, vol. 28, no. 7, pp. 775-783, 2005.

[50] W. Y. Liao, T. H. Tsai, T. Y. Ho, Y. W. Lin, C. Y. Cheng, and C. L. Hsieh, "Neuroprotective effect of paeonol mediates anti-inflammation via suppressing toll-like receptor 2 and toll-like receptor 4 signaling pathways in cerebral ischemiareperfusion injured rats," Evidence-Based Complementary and Alternative Medicine, vol. 2016, Article ID 3704647, 12 pages, 2016.

[51] Q. Zhang and M. Ye, "Chemical analysis of the Chinese herbal medicine Gan-Cao (licorice)," Journal of Chromatography. A, vol. 1216, no. 11, pp. 1954-1969, 2009.

[52] S. Matsui, H. Matsumoto, Y. Sonoda et al., "Glycyrrhizin and related compounds down-regulate production of inflammatory chemokines IL-8 and eotaxin 1 in a human lung fibroblast cell line," International Immunopharmacology, vol. 4, no. 13, pp. 1633-1644, 2004.

[53] T. Genovese, M. Menegazzi, E. Mazzon et al., "Glycyrrhizin reduces secondary inflammatory process after spinal cord compression injury in mice," Shock, vol. 31, no. 4, pp. 367375, 2009.

[54] H. Zhao, S. L. Wang, L. Qian et al., "Diammonium glycyrrhizinate attenuates $\mathrm{A} \beta_{1-42}$-induced neuroinflammation and regulates MAPK and NF-kB pathways in vitro and in vivo," CNS Neuroscience \& Therapeutics, vol. 19, no. 2, pp. 117-124, 2013.

[55] R. Tanemoto, T. Okuyama, H. Matsuo, T. Okumura, Y. Ikeya, and M. Nishizawa, "The constituents of licorice (Glycyrrhiza uralensis) differentially suppress nitric oxide production in interleukin-1 $\beta$-treated hepatocytes," Biochemistry and Biophysics Reports, vol. 2, pp. 153-159, 2015.

[56] A. Cheng, F. Wan, J. Wang, Z. Jin, and X. Xu, "Macrophage immunomodulatory activity of polysaccharides isolated from Glycyrrhiza uralensis fish," International Immunopharmacology, vol. 8, no. 1, pp. 43-50, 2008.

[57] H. Gong, B. K. Zhang, M. Yan et al., "A protective mechanism of licorice (Glycyrrhiza uralensis): isoliquiritigenin stimulates detoxification system via Nrf2 activation," Journal of Ethnopharmacology, vol. 162, pp. 134-139, 2015.

[58] D. Calzia, M. Oneto, F. Caicci et al., "Effect of polyphenolic phytochemicals on ectopic oxidative phosphorylation in rod outer segments of bovine retina," British Journal of Pharmacology, vol. 172, no. 15, pp. 3890-3903, 2015.

[59] S. J. Jeong, H. S. Lim, C. S. Seo et al., “Traditional herbal formula Jakyakgamcho-tang (Paeonia lactiflora and Glycyrrhiza uralensis) impairs inflammatory chemokine production by inhibiting activation of STAT1 and NF- $\mathrm{BB}$ in HaCaT cells," Phytomedicine, vol. 22, no. 2, pp. 326-332, 2015.

[60] B. Kaltschmidt, C. Kaltschmidt, T. G. Hofmann, S. P. Hehner, W. Droge, and M. L. Schmitz, "The pro- or anti-apoptotic function of NF- $\kappa \mathrm{B}$ is determined by the nature of the apoptotic stimulus," European Journal of Biochemistry, vol. 267, no. 12, pp. 3828-3835, 2000.

[61] E. Yang, J. Zha, J. Jockel, L. H. Boise, C. B. Thompson, and S. J. Korsmeyer, "Bad, a heterodimeric partner for Bcl-XL and Bcl-2, displaces Bax and promotes cell death," Cell, vol. 80, no. 2, pp. 285-291, 1995.
[62] K. Wang, X. M. Yin, D. T. Chao, C. L. Milliman, and S. J. Korsmeyer, "BID: a novel BH3 domain-only death agonist," Genes \& Development, vol. 10, no. 22, pp. 2859-2869, 1996.

[63] X. Liu, C. N. Kim, J. Yang, R. Jemmerson, and X. Wang, "Induction of apoptotic program in cell-free extracts: requirement for dATP and cytochrome c," Cell, vol. 86, no. 1, pp. 147157, 1996.

[64] J. W. Mandell and G. A. Banker, "A spatial gradient of tau protein phosphorylation in nascent axons," The Journal of Neuroscience, vol. 16, no. 18, pp. 5727-5740, 1996.

[65] J.-H. Cho and G. V. W. Johnson, "Glycogen synthase kinase $3 \beta$ phosphorylates tau at both primed and unprimed sites: differential impact on microtubule binding," Journal of Biological Chemistry, vol. 278, no. 1, pp. 187-193, 2003.

[66] J. Z. Wang and F. Liu, "Microtubule-associated protein tau in development, degeneration and protection of neurons," Progress in Neurobiology, vol. 85, no. 2, pp. 148-175, 2008.

[67] D. P. Hanger, B. H. Anderton, and W. Noble, "Tau phosphorylation: the therapeutic challenge for neurodegenerative disease," Trends in Molecular Medicine, vol. 15, no. 3, pp. 112-119, 2009. 


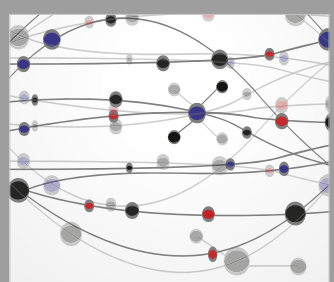

The Scientific World Journal
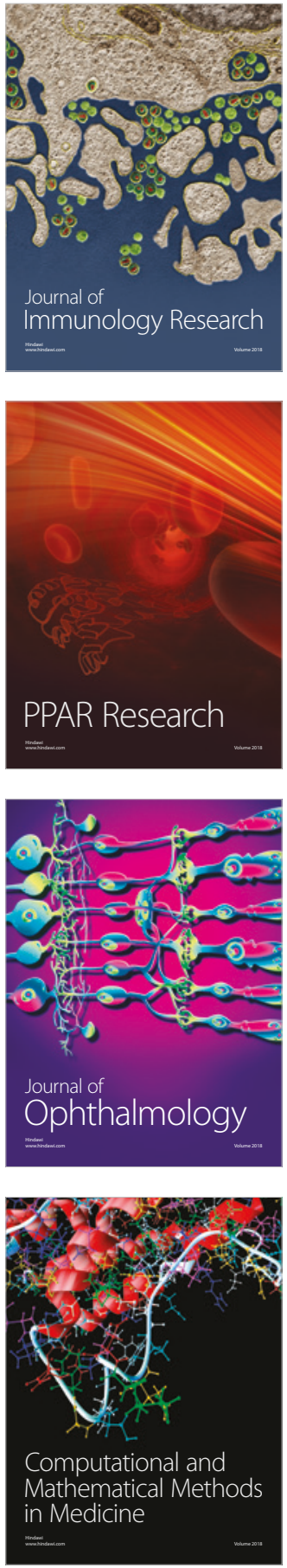

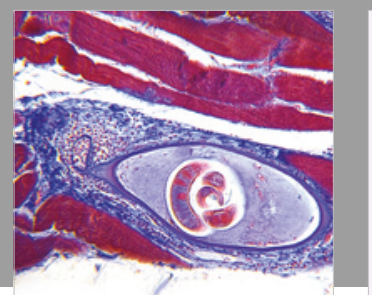

Gastroenterology Research and Practice

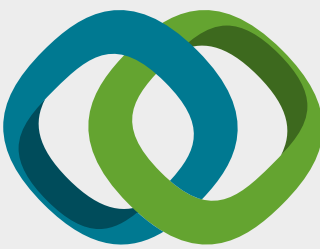

\section{Hindawi}

Submit your manuscripts at

www.hindawi.com
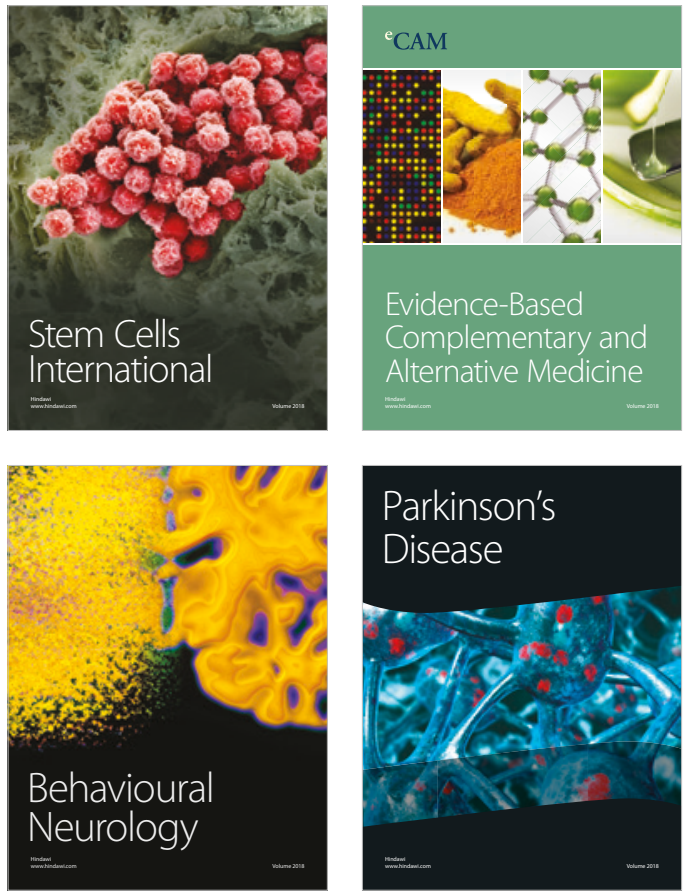

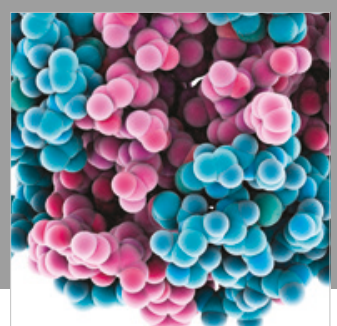

ournal of

Diabetes Research

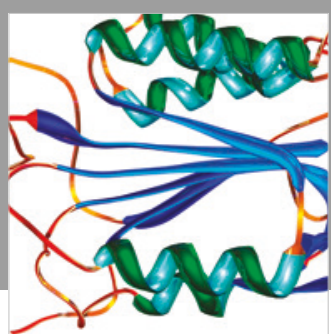

Disease Markers
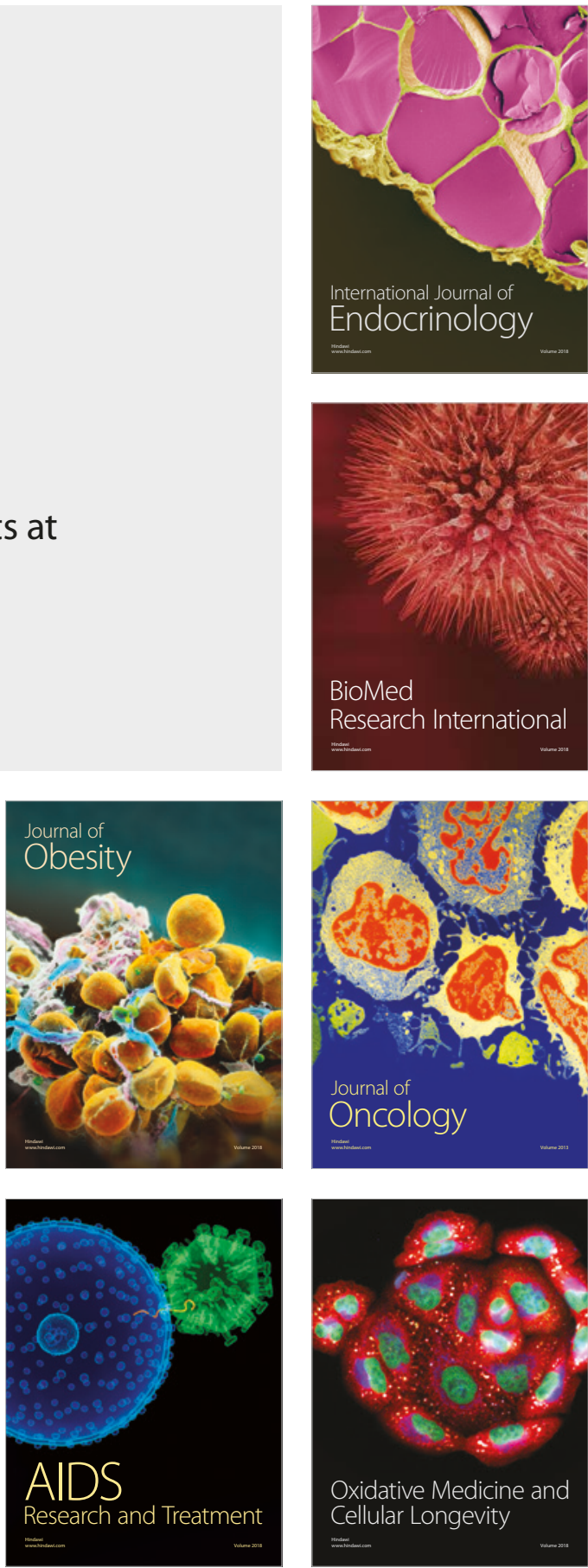